\title{
Static and dynamic numerical simulations of a generic UCAV configuration with and without control devices
}

\author{
Andreas Schütte ${ }^{1}$ \\ German Aerospace Center (DLR), Braunschweig, Germany \\ Kerstin C. Huber ${ }^{2}$ \\ German Aerospace Center (DLR), Braunschweig, Germany \\ Okko Joost Boelens ${ }^{3}$ \\ National Aerospace Laboratory (NLR), Amsterdam, The Netherlands
}

\begin{abstract}
A contribution for the assessment of the static and dynamic aerodynamic behavior of a generic UCAV configuration with control devices using CFD methods is given. For the CFD simulations the unstructured grid based DLR TAU-Code and the structured grid based NLR solver ENSOLV are used. The numerical methods are verified by experimental wind tunnel data. The current investigations should provide a contribution to assess the prediction capability of control device effectiveness using CFD methods. The presented computational results for the assessment will be validated by dedicated experimental data. Furthermore, it should support the understanding of the flow physics around the trailing edge control devices of highly swept configurations with a vortex dominated flow field. Design requirements should be able draw by analyzing the interaction between the vortical flow and the control devices. The present work is part of the NATO STO/AVT Task Group AVT-201 on Stability and Control prediction methods.
\end{abstract}

\section{Nomenclature}

$\begin{array}{lll}\alpha & =\text { AoA, Angle of attack }\left[^{\circ}\right] \\ \beta & =\text { AoS, Angle of side slip }\left[^{\circ}\right] \\ \eta & =\text { Flap deflection angle }\left[^{\circ}\right] \\ \Theta & =\text { Pitch angle }\left[^{\circ}\right] \\ \Psi & =\text { Yaw angle }\left[^{\circ}\right] \\ V_{\infty} & =\text { On-flow velocity }[\mathrm{m} / \mathrm{s}] \\ F & = & \text { Frequency }[\mathrm{Hz}] \\ T & = & \text { Time }[\mathrm{s}] \\ K & = & \text { Reduced frequency } 2 \pi \cdot f \cdot c_{r e f} / V \\ D o F & = & \text { Degree of Freedom } \\ C F R P & = & \text { Moment Reference Point }[\mathrm{m}] \\ M R P & = & \text { Angle of Attack }\left[{ }^{\circ}\right] \\ A o A & = & \text { Angle of Sideslip }\left[{ }^{\circ}\right] \\ A o S & = & \text { Reylart-Allmaras turb. model } \\ S A & = & \text { Reference relation area }\left[\mathrm{m}^{2}\right] \\ R S M & = & \text { Reference length }[\mathrm{m}] \\ A & = & \text { Root chord }[\mathrm{m}] \\ c_{r e f} & & \end{array}$

\begin{tabular}{|c|c|c|}
\hline$s$ & $=$ & Half span $[\mathrm{m}]$ \\
\hline$x$ & $=$ & Chord wise coordinate $[\mathrm{m}]$ \\
\hline$z$ & $=$ & Vertical coordinate $[\mathrm{m}]$ \\
\hline$y$ & $=$ & Span wise coordinate $[\mathrm{m}]$ \\
\hline$\rho_{\infty}$ & $=$ & Density $\left[\mathrm{kg} / \mathrm{m}^{3}\right]$ \\
\hline$p_{\infty}$ & $=$ & Static pressure $\left[\mathrm{N} / \mathrm{m}^{2}\right]$ \\
\hline$q_{\infty}$ & $=$ & Dynamic pressure $\left[\mathrm{N} / \mathrm{m}^{2}\right] 0.5 \cdot \rho_{\alpha} \cdot V_{\infty}{ }^{2}$ \\
\hline$c_{p}$ & $=$ & Pressure coefficient $[-] p-p_{\propto} / q_{\propto}$ \\
\hline$c_{L}$ & $=$ & Lift coefficient $[-] L /\left(q_{\infty} \cdot A\right)$ \\
\hline$c_{D}$ & $=$ & Drag coefficient (AE) $[-] D /\left(q_{\propto} \cdot A\right)$ \\
\hline$c_{S}$ & $=$ & Side force coefficient (AE) $[-] s /\left(q_{\propto} \cdot A\right)$ \\
\hline$c_{m}$ & $=$ & Pitch moment coefficient (AE) $[-] M /\left(q_{\propto} \cdot A \cdot c_{r e f}\right)$ \\
\hline$c_{l}$ & $=$ & Roll moment coefficient (AE) $[-] l /\left(q_{\infty} \cdot A \cdot s\right)$ \\
\hline$c_{n}$ & $=$ & Yaw moment coefficient (AE) $[-] n /\left(q_{\propto} \cdot A \cdot s\right)$ \\
\hline$c_{z}$ & $=$ & Normal force coefficient $(\mathrm{MF})[-] F_{z} /\left(q_{\propto} \cdot A\right)$ \\
\hline$c_{y}$ & $=$ & Side force coefficient $(\mathrm{MF})[-] F_{y} /\left(q_{x} \cdot A\right)$ \\
\hline$c_{m x}$ & $=$ & Roll moment coefficient (MF) $[-] M_{x} /\left(q_{\infty} \cdot A \cdot c_{r e f}\right)$ \\
\hline$c_{m y}$ & $=$ & Pitch moment coefficient (MF) $[-] M_{y} /\left(q_{\propto} \cdot A \cdot s\right)$ \\
\hline$c_{m z}$ & $=$ & Yaw moment coefficient (MF) $[-] M_{z} /\left(q_{\propto} \cdot A \cdot s\right)$ \\
\hline
\end{tabular}

\footnotetext{
${ }^{1}$ Research Scientist, DLR Institute of Aerodynamics and Flow Technology, Lilienthalplatz 7, D-38108 Braunschweig, Germany, andreas.schuette@dlr.de, AIAA Senior Member (Corresponding author)

2 Research Scientist, DLR Institute of Aerodynamics and Flow Technology, Lilienthalplatz 7, D-38108 Braunschweig, Germany, kerstin.huber@dlr.de

3 R\&D Engineer, Applied Computational Fluid Dynamics, Department of Flight Physics and Loads, Aerospace Vehicles Division, boelens@nlr.nl
} 


\begin{tabular}{|c|c|c|c|c|c|}
\hline$L O B$ & $=$ & Left Outboard Trailing Edge Flap & $L E$ & $=$ & Leading Edge \\
\hline$L I B$ & $=$ & Left Inboard Trailing Edge Flap & $S L E$ & $=$ & Sharp Leading Edge \\
\hline$R I B$ & $=$ & Right Inboard Trailing Edge Flap & $R L E$ & $=$ & Round Leading Edge \\
\hline$R O B$ & $=$ & Right Outboard Trailing Edge Flap & $R L E-F T$ & $=$ & Round Leading Edge - Fixed \\
\hline$B L$ & $=$ & Base Line (no CS deflection) & & & Transition \\
\hline$C S$ & $=$ & Control Surface & CAWAPI & $=$ & Cranked Arrow Wing \\
\hline$A V T$ & $=$ & Applied Vehicle Technology & & & Aerodynamics Project Intern. \\
\hline STO & $=$ & Science and Technology Organization & $S A C C O N$ & $=$ & Stability And Control \\
\hline RTO & $=$ & Research and Technology Organization & & & CONfiguration \\
\hline
\end{tabular}

\section{Introduction}

$\mathrm{T}$

HE understanding and the prediction of the flow physics and stability and control behavior of modern fighter type configurations at medium and high AoA are and remain key to superior maneuverability and performance. Recent UCAV configurations and design studies use medium to highly swept wings with round or variable leading edge geometries. The performance and signature considerations often result in medium leading edge sweep angles of $45^{\circ}-60^{\circ}$. The design constrains of future agile and low observable UCAV configurations are a compromise between a minimum cross section and an advanced flight performance to achieve long range with remaining agility.

The plan form can vary from a pure delta to a diamond and even a lambda wing configuration. All of these configurations are more or less blended wing bodies with a relatively small thickness ratio of the inner wing/fuselage part. The aerodynamics of these configurations is characterized by a nonlinear aerodynamic behavior dominated by a complex vortical flow field on the upper side of the wing. The progression of these vortices depend on the sweep angle, the leading edge geometry, the plan form shape and the on-flow conditions such as angle of attack, Mach and Reynolds number.

The challenge of the design is to achieve high agility and flight performance without any vertical tail plane to avoid the increase of the radar cross section. All control forces and moments should be provided by control effectors which do not especially change the radar cross section at all or only at points in the flight envelope where no threat could appear, during takeoff, landing or outside of the operating range. As long as no unconventional control devices are available it is necessary to look at conventional trailing edge devices for pitch, roll and yaw control. For flight conditions at small angles of attack these conventional trailing edge devices work quite well as applied in several configurations like the Boeing B2 aircraft. For medium to high angles of attack with a vortical flow field on the upper wing of the configuration these kinds of control surface setups might not work or are less efficient as in flight regimes with fully attached flow.

The understanding and prediction of the flow physics of delta wing configurations with round or variable leading edges is still challenging. Within the NATO Science and Technology Organization/Applied Vehicle Technology Panel (STO/AVT) Task Groups several configurations have been tested in the wind tunnel and numerical investigations have been performed to predict the overall flight physics and stability and control coefficients. The progression and location of the vortical flow around delta wings with round leading edges has been investigated in the Vortex Flow Experiment 2 (VFE-2) within the NATO RTO/AVT-113 Task Group. ${ }^{1-3}$ The flow around a $65^{\circ}$ delta wing with sharp and round leading edges is analyzed by an integrated approach of experimental wind tunnel tests and numerical simulations. Among others, numerical results using the DLR TAU-Code have been described by Schütte and Lüdeke ${ }^{4}$ and summaries of lessons learned are given by Fritz and Cummings ${ }^{5}$ as well as by Luckring and Hummel. ${ }^{6}$ All results are published in the RTO Final Report by Lamar and Hummel et al. ${ }^{7}$ The result of the VFE-2 is a basic understanding of the vortical flow structure and aerodynamics of delta wing configurations with round leading edges. The report also draws out the prediction capability with CFD methods in comparison to experimental data as well as limitations regarding the prediction of the complex aerodynamics with CFD methods.

A second configuration within the AVT-113 Task Group is a real fighter type configuration, the F-16 CAWAPI which was simulated with CFD RANS methods as well. The results are published in the final report of AVT-113 ${ }^{7}$ and among others by Boelens et al. ${ }^{8}$, Görtz et al. ${ }^{9}$ and Fritz et al. ${ }^{10}$ In addition, in Schütte and Boelens et al. ${ }^{11}$ results performed in the framework of the AVT-161 Task Group are simulating the X-31 configuration in comparison to experimental wind tunnel data. Several results are presented using the DLR-TAU and ENSOLV RANS CFD-Codes for both applications, the X-31 and the CAWAPI F-16XL configuration. 
Within the AVT-161 Task Group the plan form of the current UCAV configuration "SACCON" has been developed. In AVT-161 the Stability and Control prediction capabilities using CFD methods have been investigated for the configuration without control devices. The research group provided an extended experimental data base for computer code validation purposes ${ }^{12,13}$ to analyze the flow physics, aerodynamic behavior as well as the S\&C parameters. The results are presented in the final report of the AVT-161 Task Group. ${ }^{14}$ The objectives and strategy of the research group are described by Cummings and Schütte. ${ }^{15}$ A detailed description of the flow physics and evaluation of the S\&C prediction capabilities of the SACCON configuration is given by Schütte et al. ${ }^{16}$ and Frink et al. $^{17}$

In the follow on program within the NATO STO/AVT-201 Task Group on "Extended Stability and Control Prediction Methods for NATO Air Vehicles"18,19 the SACCON UCAV configuration has been modified and trailing edge control devices have been implemented. A description of the model configurations and experimental results from the wind tunnel tests are presented for the low speed tests by Huber et al. ${ }^{20}$ and Vicroy et al. ${ }^{21}$ and for the high speed investigations by Rein et al. ${ }^{22}$

In this paper the prediction capabilities of high fidelity, Reynolds-averaged Navier-Stokes based CFD methods of the flow field and aerodynamic behavior of the SACCON configuration with control devices will be shown. The report starts with the prediction of the flow physics of the clean configuration (BL-no flap deflection) followed by a comparison between different control surface settings and the base line (BL) configuration without flap deflection. The differences between numerical simulations and experimental data will be discussed as well as sensitivities regarding the numerical approach, regarding the CFD method and applied turbulence models. Finally, comparisons between numerical and experimental simulations of dynamic pitch maneuvers will be presented and discussed.

\section{UCAV Model Configuration and Experimental Approach}

The DLR-F19 configuration is part of a model family based on the geometry of the generic UCAV configuration SACCON developed within NATO STO/AVT research activities. The DLR-F19 configuration, as shown in Figure $\mathbf{1}$, has control surfaces located on the left and right hand side along the trailing edge of the outer wings and at the wing tips. The present investigation takes the configuration using the trailing edge control surfaces into account only.

The hinch line of the trailing edge control surfaces is located at $75 \%$ of the outer wing cord $\mathrm{c}_{\text {ref }}$ and the control surface deflections for all control surfaces taken into account are $\eta=-20^{\circ}, 0^{\circ}$ and $+20^{\circ}$. The reference geometry parameters are shown in Figure 2. For the Reynolds number and the pitching moment the reference length is the outer wing chord $c_{r e f}$ and for the rolling and yawing moment the half span s. The point of rotation (PoR) for the static and dynamic measurement is located where the belly sting support is connected to the lower rear part of the model. All forces and moments are related to the moment reference point (MRP) at $\mathrm{x}=0.6 \mathrm{~m}$. A detailed description of the design process from the BL SACCON configuration to the DLR-F19 with control devices is given by Liersch and Huber. ${ }^{23}$

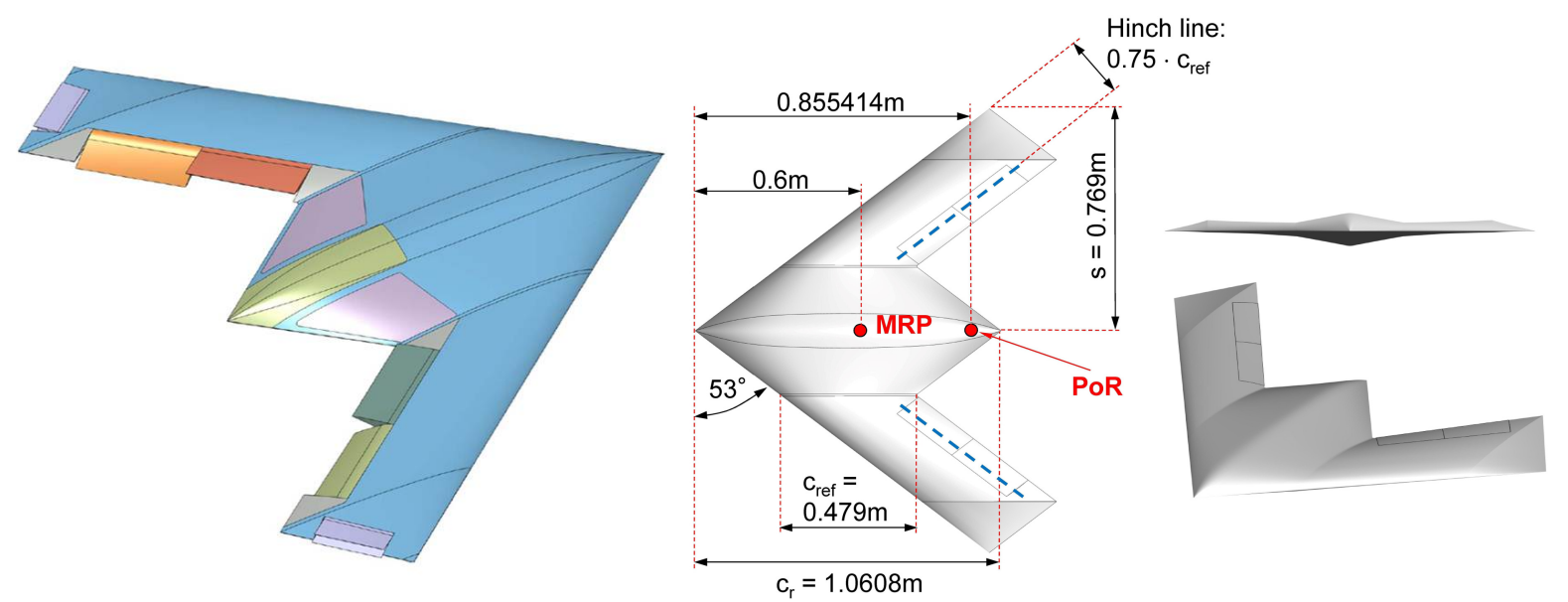

Figure 1. DLR-F19 configuration.

Figure 2. Reference geometry parameters for the DLR-F19 configuration. 
Static and dynamic forces, moments and surfaces pressure measurements have been performed in the DNW$\mathrm{NWB}^{24}$ low speed wind tunnel facility in Braunschweig with the DLR-F19 configuration. The wind tunnel tests have been performed in the closed tests section and the model was mounted on a belly sting support located on the lower side of the model, as depicted in Figure 3. The belly sting support is mounted on a 6 Degree-of-freedom (DoF) Model Positing Mechanism (MPM) setup within the DNW-NWB to allow for maneuver simulations within the wind tunnel. ${ }^{24}$

Figure 4 shows the location of the pressure ports on the upper and lower side of the model as well as the sign convention of the control surface deflections.

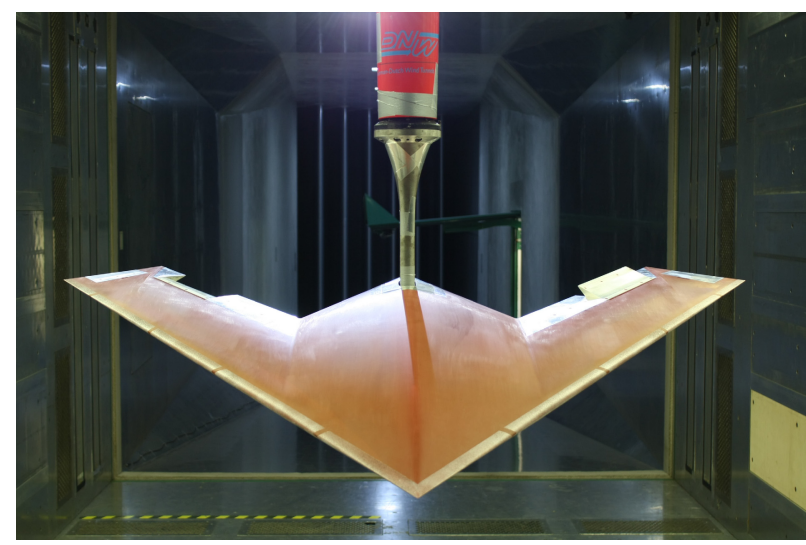

Figure 3. DLR-F19 generic UCAV wind tunnel model with trailing edge control devices. Belly sting support on the lower rear side of the model.

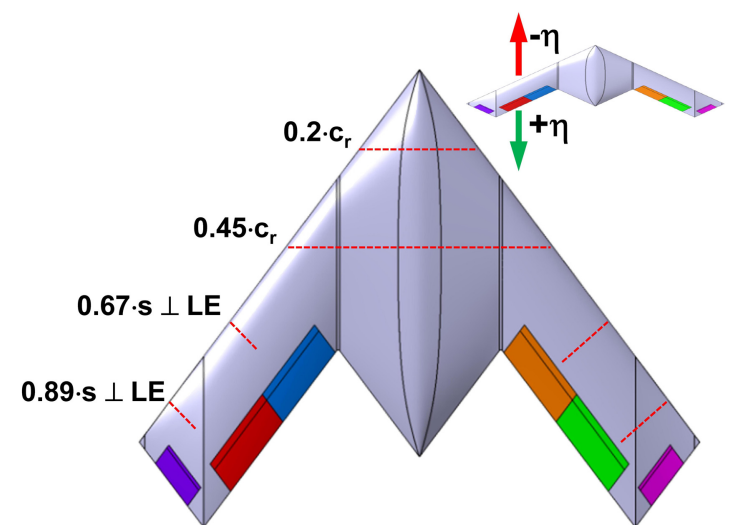

Figure 4. Position of the pressure ports and sign convention for the deflection of the control surfaces.

For comparisons between the numerical simulations and experiments a common static and dynamic test case matrix was defined in cooperation with the STO/AVT-201 Task Group. The matrix contains test cases for the base line configuration in comparison with cases where control surface deflections have been established. Both static and dynamic pitch and yaw maneuvers have been defined. A detailed description of the experiments and experimental results presented in this paper can be found in Huber et al. ${ }^{20}$ and Vicroy et al. ${ }^{21}$

\section{Numerical Approach}

Within the paper two different computational RANS methods have been applied. The DLR TAU-Code based on a cell-vertex scheme using hybrid computational grids and the NLR CFD solver ENSOLV based on a cell-centered scheme using a structured computational grid approach.

\section{A. DLR Flow Solver TAU}

One flow solver used in the present paper is the DLR TAU-Code, a CFD software developed by the DLR Institute of Aerodynamics and Flow Technology. ${ }^{25-28}$ The TAU-Code solves the compressible, three-dimensional, time-accurate Reynolds-Averaged Navier-Stokes equations using a finite volume formulation. The code is based on a hybrid unstructured-grid approach to be able to handle structured and hybrid computational grids, which makes use of the advantages offered by prismatic grid structures applied to resolve the viscous shear layer close to the wall, and the flexibility in grid generation offered by unstructured grids.

The compressible equations in the TAU-Code in full conservation form are discretized in space by a secondorder accurate finite-volume method. The TAU-Code basic version is using a cell-vertex metric with a dual-grid approach in order to make the flow solver independent from the cell types used in the initial grid. Within the TAUCode a typical Jameson-type, Matrix dissipation and several upwind schemes can be used. For the current applications in all simulations the Matrix dissipation has been applied.

The TAU-Code consists of several different modules. One of these modules is the motion module which allows generating any kind of rigid body motion as well as relative motion between different parts of the computational models. The motion can be described by polynomial and Fourier functions as well as by motion files provided by python based interfaces.

The current simulations have been performed using the steady state and unsteady dual time-stepping approach. The dual time stepping approach was used for the dynamic maneuver simulations as well as for steady state 
simulations by averaging over a certain time period. The latter was always applied in cases where no steady state solution could be achieved.

For the numerical simulations two physical RANS models have been used. A first approach uses a version the one equation Spalart-Allmaras turbulence $\operatorname{model}^{29}$ SA-neg. The SA-neg version allows particularly negative values of the transport turbulence quantaties. ${ }^{30}$ This modification should lead to a more efficient solution of the equation without changing the dedicated aerodynamic solution.

The main turbulence model used for the TAU-Code simulations is a Reynolds-Stress turbulence model (RSM). ${ }^{31,32}$ The RSM model actually applied is a modified SSG/LLR- $\omega$ model with a different formulation of the length scale variable $\omega$ transferred to $g=1 / \sqrt{ } \omega$. This transformation should provide a more stable solution close to the wall which leads i.e. to a reduced dependency of the computational grid at the wall. A first idea of this transformation can be found in a publication by Kalitzin. ${ }^{33,34}$

In the following the two specific turbulence model versions for the DLR TAU-Code will be abbreviated by SA and RSM respectively.

\section{B. NLR Flow Solver ENSOLV}

The flow solver ENSOLV, which is part of NLR's in-house developed flow simulation system ENFLOW, ${ }^{35,36}$ is capable of solving the Euler, Reynolds-Averaged Navier-Stokes (RANS), Large Eddy Simulation (LES) and hybrid RANS-LES (XLES) equations on multi-block structured grids for arbitrary configurations. The configuration can be either fixed or moving relative to an inertial reference frame, and can be either rigid or flexible. The compressible equations in full conservation form are discretized in space by a second-order accurate, cell-centered, finite-volume method, using multi-block structured grids, central differences, and matrix artificial diffusion. The artificial diffusion consists of a blending of second-order and fourth-order differences with a Jameson-type shock sensor for the basic flow equations and a Total Variation Diminishing (TVD) discontinuity sensor for the turbulence model equations.

The current simulations have been performed as steady flow simulations, for which the discretized timedependent system of equations is integrated toward the steady state solution using a five-stage explicit Runge-Kutta scheme. Local-time stepping and multi-grid acceleration techniques are applied.

Several turbulence models are present in the flow solver ENSOLV, including the Turbulent Non-Turbulent (TNT) k- $\omega$ model, ${ }^{37,38}$ the Explicit Algebraic Reynolds Stress (EARS) model and a sub-grid model for simulation using the hybrid RANS-LES equations for eXtra-Large Eddy Simulation (XLES). ${ }^{39-40}$ The simulations presented in this paper have been performed employing the EARS model.

\section{Computational Grids \\ C.1 Hybrid Grids}

The hybrid unstructured grids used for the simulations with the DLR TAU-Code have been created with the hybrid grid generator Centaur, developed by CentaurSoft. ${ }^{41}$ Table 1 is listing the different cases to be discussed in this paper by using the CFD solver DLR TAU-Code. The belly sting support has been taken into account for most of the cases. In simulations where this is not the case it will be explicitly pointed out in the text.

\begin{tabular}{|l|c|c|c|c|c|c|c|}
\hline & $\begin{array}{c}\mathrm{LOB} \\
\eta\left[^{\circ}\right]\end{array}$ & $\begin{array}{c}\mathrm{LIB} \\
\eta\left[^{\circ}\right]\end{array}$ & $\begin{array}{c}\mathrm{RIB} \\
\eta\left[{ }^{\circ}\right]\end{array}$ & $\begin{array}{c}\text { ROB } \\
\eta\left[{ }^{\circ}\right]\end{array}$ & No. of Grid Points & No. of Elements & $\begin{array}{c}\text { No. of Prism } \\
\text { Layers }\end{array}$ \\
\hline BL - Base Line & 0 & 0 & 0 & 0 & $43.3 \cdot 10^{6}$ & $105.6 \cdot 10^{6}$ & 30 \\
\hline LIB-RIB & 0 & -20 & +20 & 0 & $42.6 \cdot 10^{6}$ & $102.2 \cdot 10^{6}$ & 30 \\
\hline LOB-ROB & -20 & 0 & 0 & +20 & $42.2 \cdot 10^{6}$ & $101.4 \cdot 10^{6}$ & 30 \\
\hline LOBLIB-RIBROB & -20 & -20 & +20 & +20 & $42.6 \cdot 10^{6}$ & $102.6 \cdot 10^{6}$ & 30 \\
\hline LOBLIB & -20 & -20 & 0 & 0 & $42.3 \cdot 10^{6}$ & $101.8 \cdot 10^{6}$ & 30 \\
\hline
\end{tabular}

Table 1. Computational grid dimensions and configurations (DLR-TAU simulations)

Figure 5 shows an example of the grid topology for the LIBLIB-RIBROB case. The prismatic layer is colored in red; further the refinement of the tetrahedral grid in the field can be seen. This refinement based on an approximation of the element size compared to vortex size is done using a field source and increases the grid resolution in the area above the upper wing where the vortices appear. The grid topology and refinement is done in the same way for all computational grids. Figure 6 shows the prismatic layer in the vicinity of the deflected control surface as well as the surface triangulation on the control device which is indicated in green. Looking at the numbers in Table 1 it can be seen that the differences of the control device setting cause only small differences in the overall number of grid points and elements. For all hybrid grids the spacing of the first prismatic layer normal to the wall is 
$0.005 \mathrm{~mm}$, resulting in a typical $\mathrm{y}+$-value of approximately one. The boundary layer is fully resolved by 30 prismatic layers. Over the entire surface of the configuration the full 30 prismatic layers can be achieved therefor no chopping of the prismatic layer occurs. To generate the grids two approaches are applied. For all grids taking the belly sting into account a re-meshing for all CS deflections have been used. If the sting is not applied a modular grid approach is used. In this case the background grid was generated for one side and mirrored to achieve a complete symmetry for the majority of the computational grid beside the CS area. The CS grid parts can be exchanged as modules which are connected to the background grid using non matching boundaries.

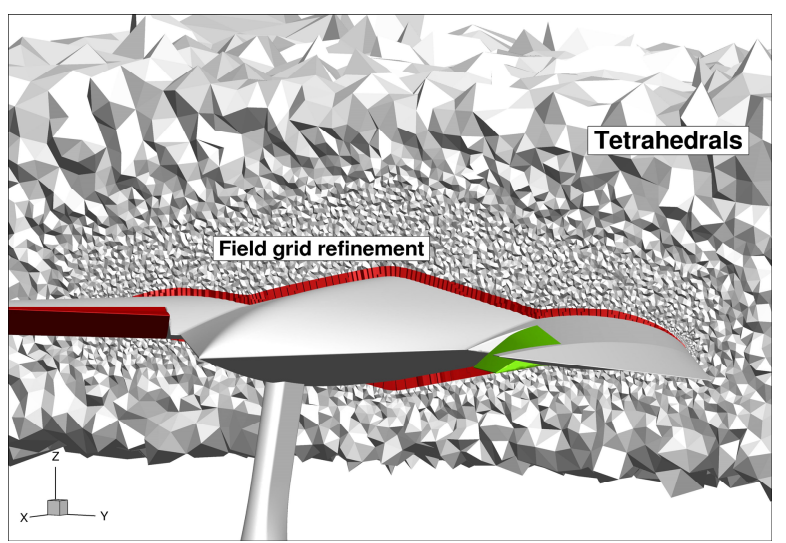

Figure 5. Hybrid unstructured grid with the prismatic layer in red and the tetrahedral field mesh, including grid refinement area.

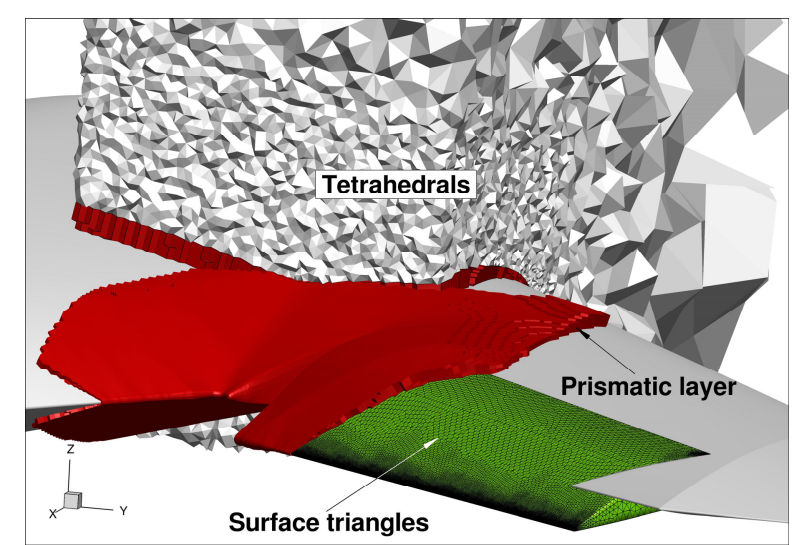

Figure 6. Detailed view of the prismatic layer, the tetrahedral field mesh and triangulation of the control devices on the right hand side.

\section{C.2 Structured Grids}

The structured (multi-block) grids have been generated using NLR's Cartesian grid mapping technique. ${ }^{42-43}$ The (semi-automatic) grid generation algorithms based on a Cartesian grid mapping technique have been developed at NLR and are part of NLR's ENFLOW flow simulation system.

To enable study on various control surface settings (i.e. the elevons) on the DLR-F19 configuration, a modular approach for the geometric modelling of the control surfaces is adopted. According to this method, the different independently moving parts of a configuration are contained in separate computational domains. The only requirement among these computational domains is that the boundary surfaces are connected properly. Different from standard methods, the grid points on the boundary surfaces do not have to match each other. The method is therefore, also called "non-matching boundary" or "sliding boundary" method when relative motion between the domains exists. To allow communication between these computational domains an interpolation method is applied on the non-matching block boundaries.

For the DLR-F19 configuration the following domains can be distinguished (see also Figure 7 and Figure 8):

i) a domain containing the main body of the DLR-F19 configuration without the control surfaces,

ii) a domain containing the inner control surface (elevon) and

iii) a domain containing the outer control surface (elevon).

Note that this method requires a small gap between the solid surface of the main DLR-F19 body and that of the control surfaces as well as between both control surfaces to allow for a "non-matching boundary" surface and a grid on both sides of this surface. For the domains with the control surfaces grids have been generated at control surface settings $\eta$ equals $-20^{\circ}, 0^{\circ}$ and $20^{\circ}$. Initially the domain containing the main body of the DLR-F19 configuration contains the half configuration. The full span configuration can be obtained by mirroring a half span configuration and adding the two half span configurations required using a "non-matching boundary" at the configuration mid plane.

Details on the grids can be found in Table 2. For these grids the spacing of the first grid point normal to the solid wall is $0.005 \mathrm{~mm}$, resulting in a typical $\mathrm{y}+$-value of approximately one. 


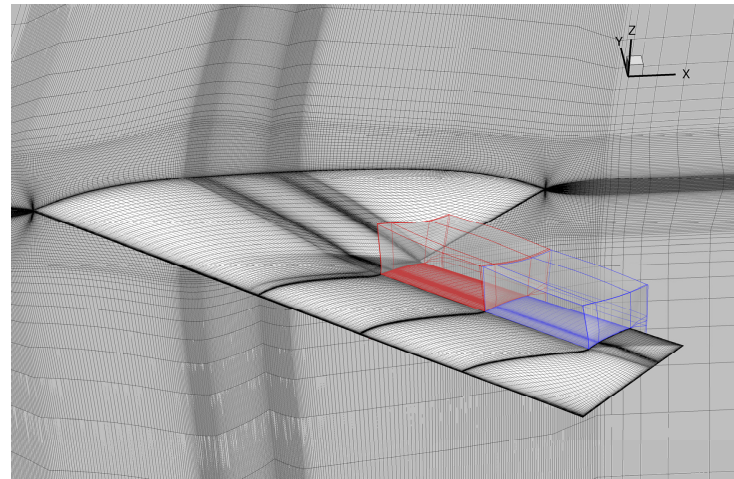

Figure 7. DLR-F19 half span configuration structured multi-block grid showing the domain for the inner control surface (red) at $\eta=0^{\circ}$ and the outer control surface (blue) at $\eta=0^{\circ}$.

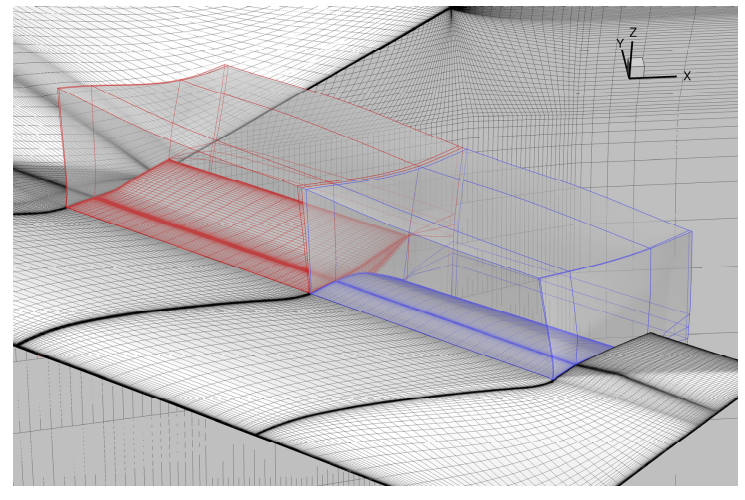

Figure 8. Detail of the DLR F-19 half span configuration structured multi-block grid showing the domain for the inner control surface (red) at $\eta=-20^{\circ}$ and the outer control surface (blue) at $\eta=20^{\circ}$.

\begin{tabular}{|l|l|r|r|}
\hline & Short description & Number of blocks & Number of grid cells \\
\hline Domain 1 & $\begin{array}{l}\text { DLR-F19 main body (half } \\
\text { configuration) }\end{array}$ & 662 & $24,924,160$ \\
\hline Domain 2 & $\begin{array}{l}\text { Inner control surface (elevon): } \eta=-20, \\
0 \text { and 20 }\end{array}$ & 46 & $1,622,016$ \\
\hline Domain 3 & $\begin{array}{l}\text { Outer control surface (elevon): } \eta=-20, \\
0 \text { and } 20^{\circ}\end{array}$ & 46 & $1,622,016$ \\
\hline
\end{tabular}

Table 2. Computational grid dimensions (NLR ENSOLV simulations). 


\section{Computational Results}

\section{A. Base Line Configuration}

First of all the flow physics of the Base Line (BL) configuration at symmetric and asymmetric on-flow condition will be discussed. The BL configuration is the reference case for all further discussions. In Figure 9 and Figure 10 the aerodynamic coefficients predicted by the DLR TAU-Code in comparison to the experiments are shown for two different turbulence models. The on-flow Mach number as for all following examples is $\mathrm{M}=0.15$ and the Reynolds number $\operatorname{Re}_{\text {cref }}=1.6 \cdot 10^{6}$. The flow physics and the resulting aerodynamic behavior are already described in detail by Schütte et al. ${ }^{16}$ However some aspects should be discussed here again: the non-linearity in the slope of the pitching moment around an AoA of $\alpha=15^{\circ}$ and the prediction of the same coefficient at higher angles of attack beyond $\alpha=$ $18^{\circ}$. The non-linearity around $\alpha=15^{\circ}$ is caused by a sudden movement of the tip vortex towards the apex along the LE. The huge dual vortex structure is causing a larger load aft of the MRP than in front of it which results in the depicted dip of the pitching moment curve. At higher AoA the load distribution is moving towards the apex due to an increasing distance of the vortex system relative to the wing surface behind the MRP and by progressing vortex breakdown.

In the previous investigation using the SA turbulence model it has been shown that the lift and drag as well as the rolling moment can be predicted quite well. For higher AoA however the one equation model is not able to predict the vortex breakdown and structure correctly and the suction peaks caused by the vortices on the upper surface are over predicted, hence are too strong. Higher order turbulence models have to be applied to be able to predict the flow physics better. In Figure 10 the RSM turbulence model is applied and it can be seen that the overestimated pitching moment for AoA higher then $\alpha=18^{\circ}$ is still existent in comparison to the SA results, but on a lower level. This aspect will be discussed again regarding the pressure distribution and flow topology.

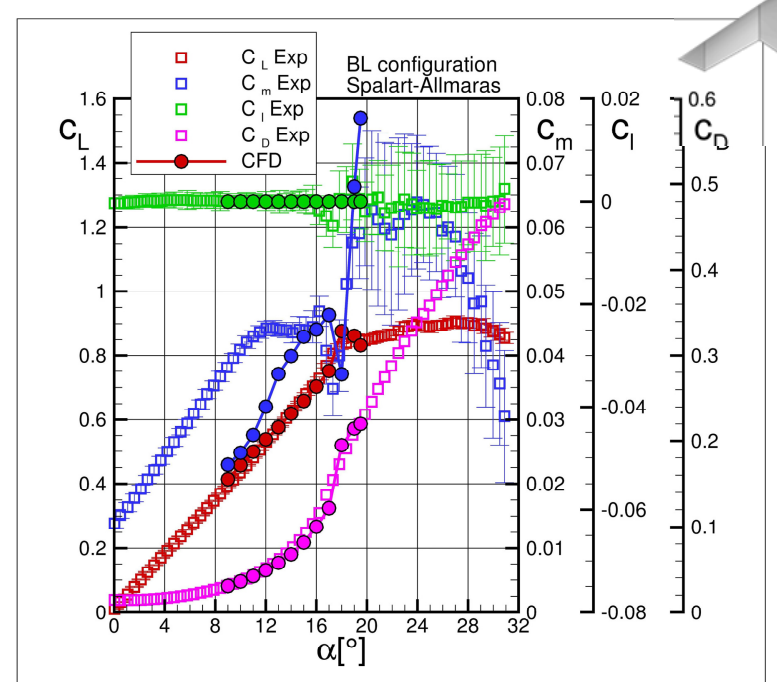

Figure 9. CFD prediction in comparison to the experiment using the Spalart-Allmaras turbulence model. Lift, drag, pitching and rolling moment coefficient using.

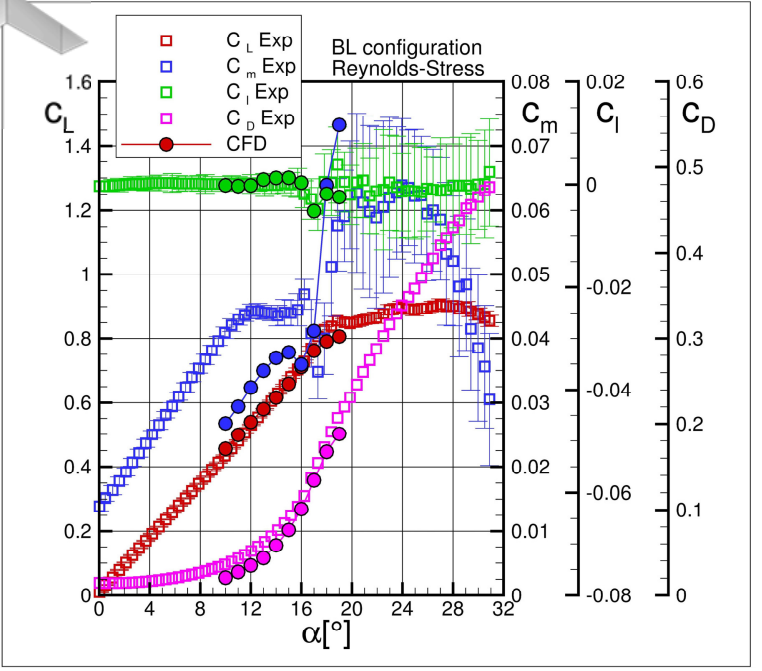

Figure 10. CFD prediction in comparison to the experiment using the Reynolds-Stress turbulence model. Lift, drag, pitching and rolling moment coefficient using.

Both approaches underestimate the pitching moment at lower AoA. One reason might be caused by the complex wake flow of the sting which is not predicted correctly either.

Figure 11 and Figure 12 show the pressure distribution at an angles of attack of $\alpha=14^{\circ}$ and $\alpha=18^{\circ}$. With respect to the upper side of the configuration the prediction of the surface pressure distribution matches qualitatively well for both turbulence models. However, it can be seen that the SA turbulence model overestimates the pressure suction peaks of the apex vortex largely. Even though the integral data matches better using the SA rather than the RSM approach the related pressure distribution is significantly off. 
Figure 12 shows the reason for the overestimated pitching moment for both cases beyond an AoA of $\alpha=18^{\circ}$. For the SA approach it is caused by the overestimated suction of the apex vortex structure. This flow physic is much better represented by the RSM turbulence model. On the other hand the pressure distribution in the tip area is underestimated due to an too early predicted onset of vortex breakdown.

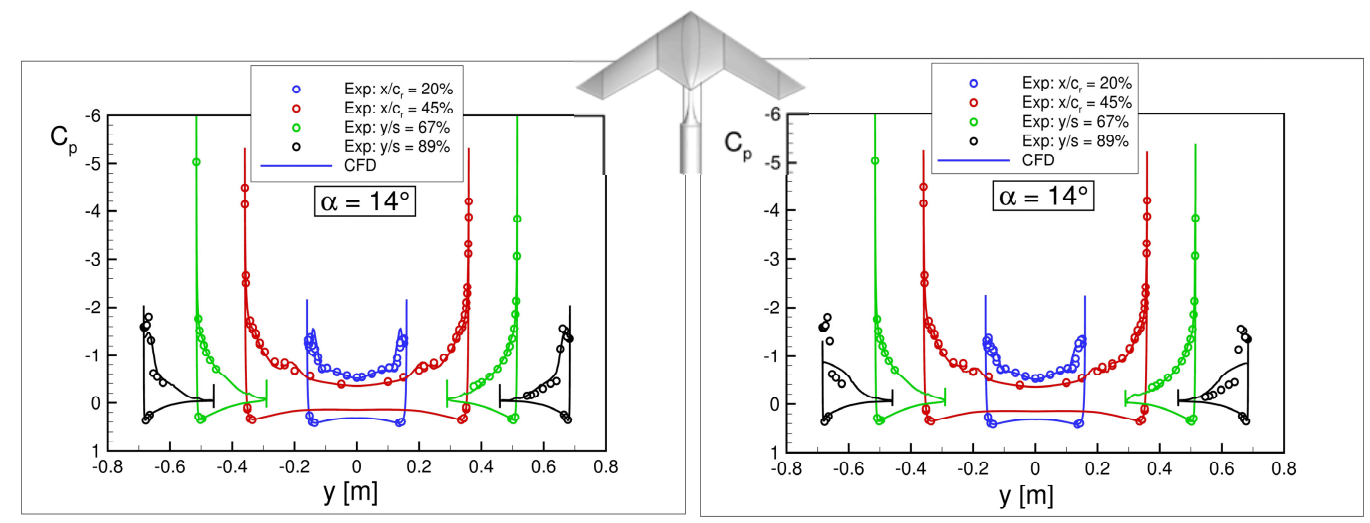

Figure 11. Comparison of the surface pressure distribution between CFD and experiment at four different $\mathrm{x}=$ const. locations. AoA $\alpha=14^{\circ} \mathrm{SA}$ (left) and RSM (right) turbulence model.

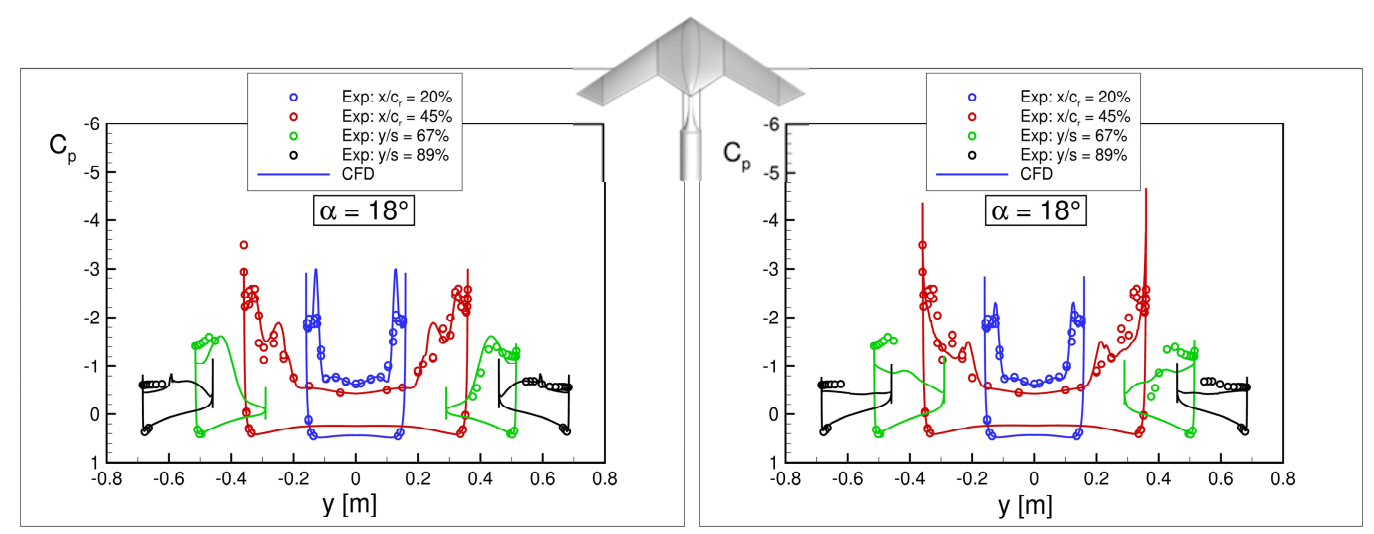

Figure 12. Comparison of the surface pressure distribution between CFD and experiment at four different $\mathrm{x}=$ const. locations. AoA $\alpha=18^{\circ} \mathrm{SA}$ (left) and RSM (right) turbulence model.

Figure 13 to Figure 16 show the corresponding flow topology on the upper side of the configuration. For $\alpha=$ $14^{\circ}$ and $\alpha=18^{\circ}$ the typical vortical flow topology is predicted by both turbulence models. For $\alpha=14^{\circ}$ the tip vortex remains at the outer wing span position and has moved towards the apex for $\alpha=18^{\circ}$. A difference between the two turbulence models can be observed comparing the vortex structure of the tip vortex for an AoA of $\alpha=14^{\circ}$. The SA model is predicting a well-structured stable tip vortex whereas for the RSM model onset of vortex breakdown can be assumed, which actually causes the weaker suction peak at the wing tip as depicted in Figure 11 on the right side. 


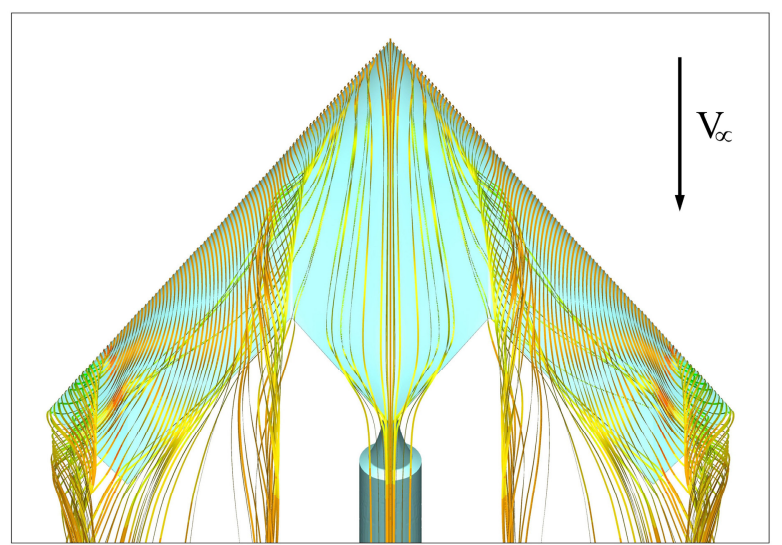

Figure 13. Predicted flow topology on the upper side of the DLR-F19 configuration. $\alpha=14^{\circ}$, SA.

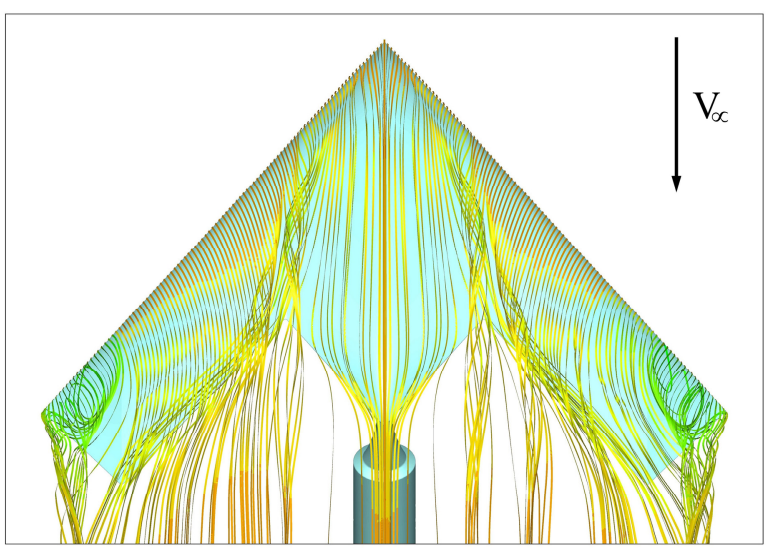

Figure 14. Predicted flow topology on the upper side of the DLR-F19 configuration. $\alpha=14^{\circ}$, RSM.

For $\alpha=18^{\circ}$ a discrete two vortex system occurs for the RSM turbulence model whereas for the SA turbulence model simulation the apex vortex is more or less collected by the huge second downstream vortex.

The predicted flow physics using the RSM turbulence model is as well not completely accurate like for the SA turbulence model. However, it can be considered from previous investigations that for the complex nonlinear flow physics, like vortex breakdown, higher order turbulence models have to be applied. Consequently the RSM turbulence model will be applied in the following DLR TAU-Code simulations.

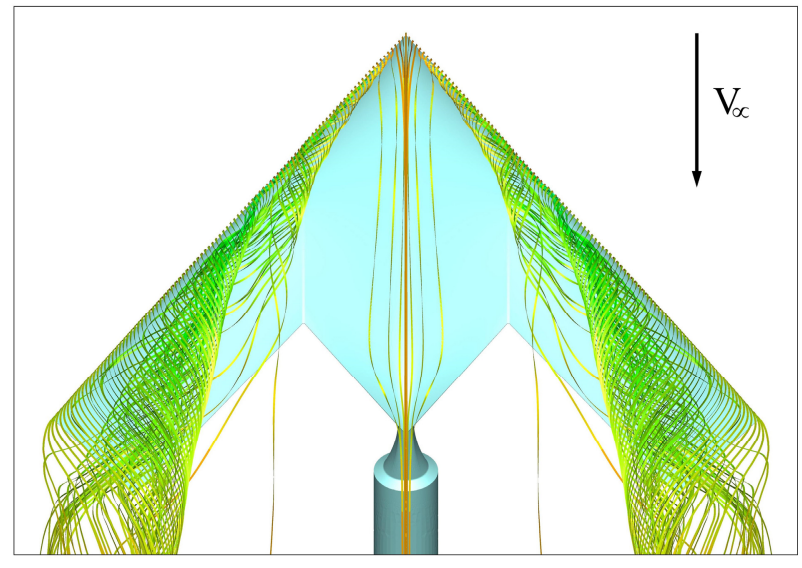

Figure 15. Predicted flow topology on the upper side of the DLR-F19 configuration. $\alpha=18^{\circ}$, SA.

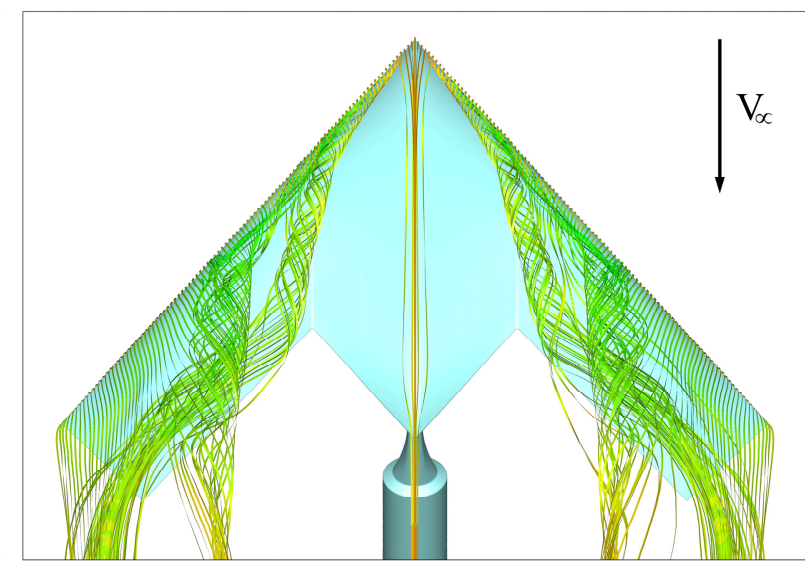

Figure 16. Predicted flow topology on the upper side of the DLR-F19 configuration. $\alpha=18^{\circ}$, RSM.

\section{B. Control Surface Deflection}

In the following section the flow physics and aerodynamic stability and control parameter for the configurations with control surface deflection will be discussed. The reference for all comparisons is the BL configuration. In this section symmetric on-flow conditions apply.

Firstly, the CFD results obtained by DLR and NLR for the full span configuration without modelling the belly sting support will be shown. Next, a method to reconstruct the full span integral data from the half span integral data will be briefly discussed. Finally, a third section will elaborate on the result obtained at DLR for the full span configuration with the belly sting support.

\section{B.1 Symmetric on-flow conditions, full span, no sting}

The simulation results discussed in this section have been obtained using the DLR TAU-Code and NLRs flow solver ENSOLV on the grids discussed before, respectively. For these simulations, the full span configuration without the belly sting support has been used. The DLR TAU-code employs the Reynolds-Stress turbulence model (RSM), whereas NLRs flow solver ENSOLV uses the Explicit Algebraic Stress model (EARSM). 
In Figure 17 and Figure 18 the aerodynamic coefficients predicted by both CFD methods (at angles of attack $\alpha=10^{\circ}$ and $\alpha=15^{\circ}$ ) in comparison to the experimental data are presented for two different control surface settings, i.e. the BL configuration in Figure 17 and the LOBLIB-RIBROB configuration in Figure 18. The results shown are completely in line with the results presented in section IV/A. The absence of the belly sting support results once more in an underprediction of the pitching moment by both methods. Both methods predict the rolling moment coefficient $\mathrm{C}_{1}$ quite well, though the DLR TAU-Code by use of a higher order turbulence model (RSM) is giving a slightly better prediction for this coefficient at $\alpha=15^{\circ}$.

Figure 19 and Figure 20 show the corresponding pressure distributions for the BL configuration and the LOBLIB-RIBROB configuration, respectively, at angles of attack $\alpha=10^{\circ}$ and $\alpha=15^{\circ}$ in comparison to the experimental data. Though for the BL configuration shown in Figure 19 both the configuration and the flow conditions are fully symmetric the experimental data shows an asymmetry in the surface pressure at the most rearward station $(0.89 \mathrm{~s}$, perpendicular to the leading edge $)$.

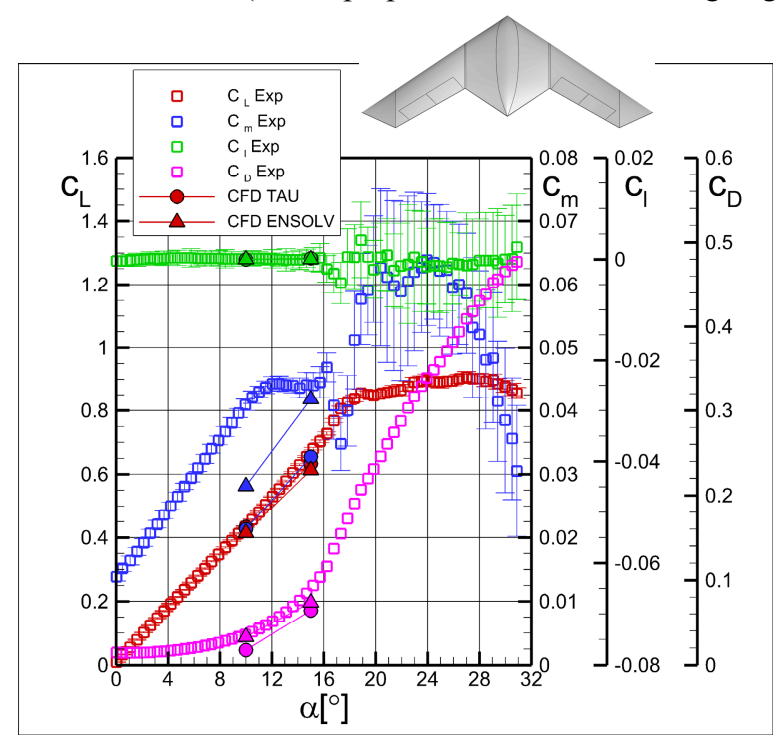

Figure 17. BL configuration: CFD prediction using DLRTAU (RSM) and NLR-ENSOLV (EARSM) (no sting support) in comparison to the experiment (with sting support). Lift, drag, pitching and rolling moment coefficient. $\alpha=$ var., $\beta=0^{\circ}$.

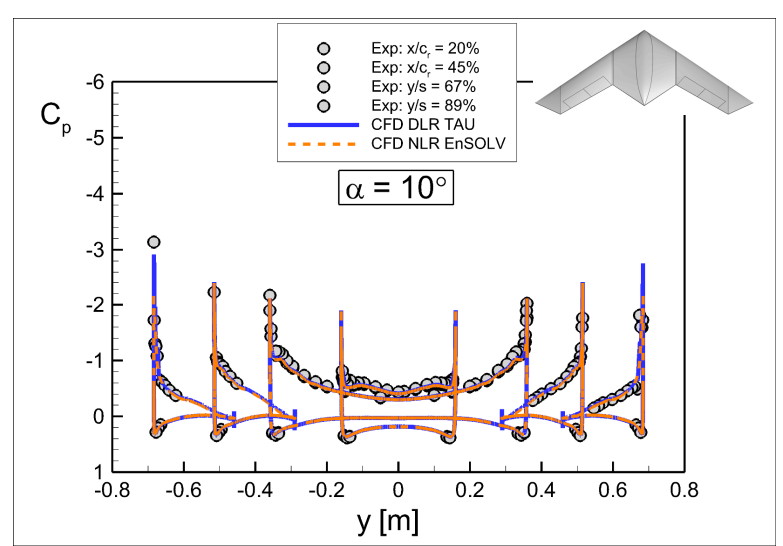

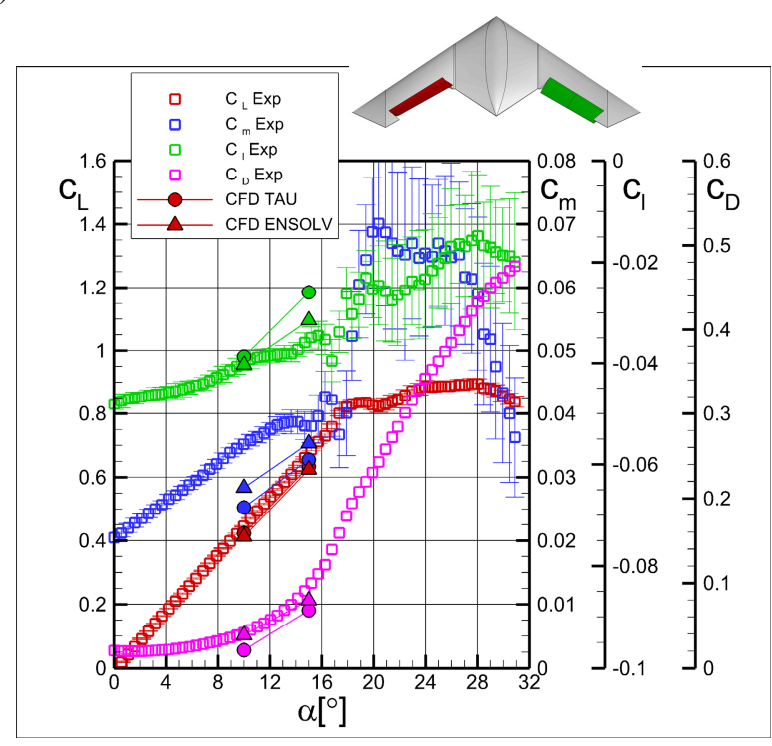

Figure 18. LOBLIB-RIBROB configuration: CFD prediction using DLR-TAU (RSM) and NLR-ENSOLV (EARSM) (no sting support) in comparison to the experiment (with sting support). Lift, drag, pitching and rolling moment coefficient. $\alpha=$ var., $\beta=0^{\circ}$.

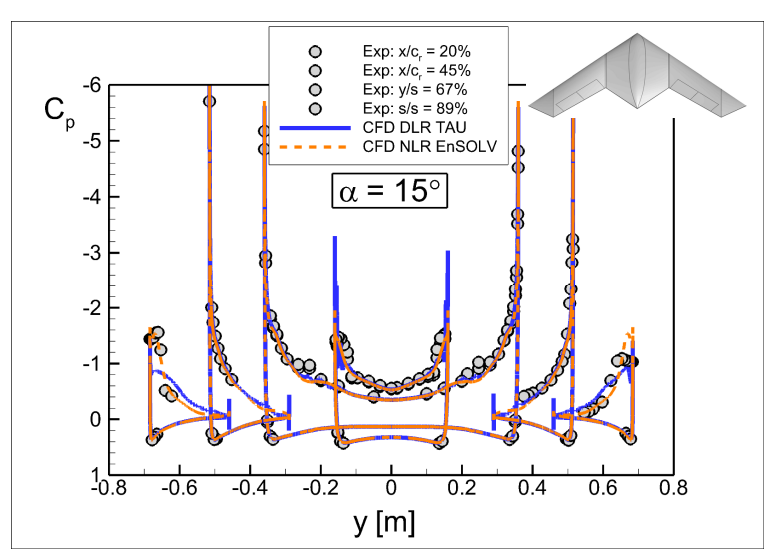

Figure 19. BL configuration: CFD prediction using DR-TAU (RSM) and NLR-ENSOLV (EARSM) (no sting support) in comparison to the experiment (with sting support). Pressure distribution. $\alpha=10^{\circ}$ and $\alpha=15^{\circ}, \beta=0^{\circ}$. 

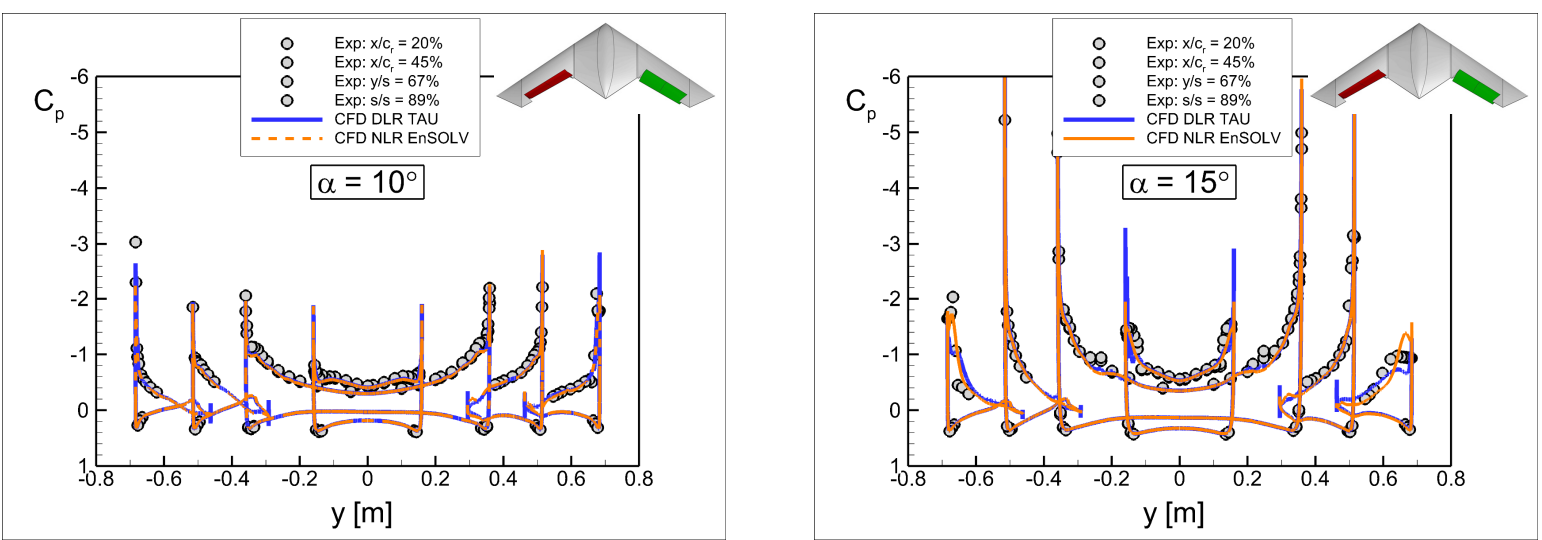

Figure 20. LOBLIB-RIBROB configuration: CFD prediction using DLR-TAU (RSM) and NLR-ENSOLV (EARSM) (no sting support) in comparison to the experiment (with sting support). Pressure distribution. $\alpha=10^{\circ}$ and $\alpha=15^{\circ}, \beta=0^{\circ}$.

The agreement between both methods and the experiment is fairly good. Both methods under predict the pressure suction peak from the apex vortex $\left(a t \mathrm{x} / \mathrm{c}_{\mathrm{r}}=45 \%\right)$ and show a more in board location of this vortex compared to the experiment. The pressure peak resulting from the leading edge vortices seems in general to be better predicted by NLRs flow solver ENSOLV with EARSM. The differences in the location and the strength of these suction peaks are the main reason of the differences in the integral forces.

Finally, in Figure 21 the differences of the S\&C values between the configuration with (LOBLIB-RIBROB) and without (BL) control surface deflection are plotted against each other.

Both methods show a fair agreement with the experimental data, indicating that such a differential approach may well be used for the purposes of S\&C database generation.

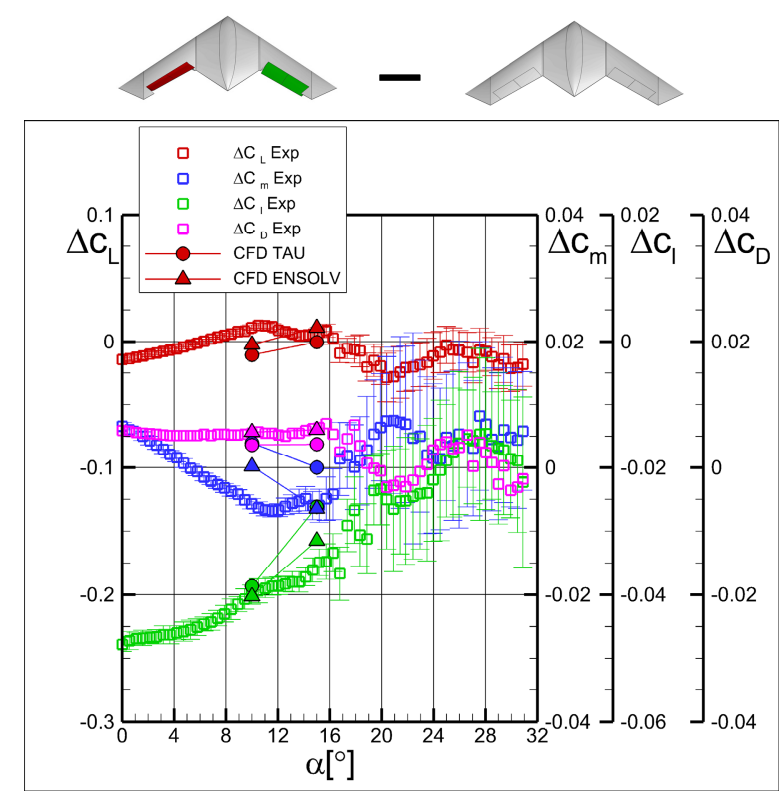

Figure 21. Differences between LOBLIB-RIBROB and BL configuration: CFD prediction using DLR-TAU (RSM) and NLR-ENSOLV (EARSM) (no sting support) in comparison to the experiment (with sting support). Lift, drag, pitching and rolling moment coefficient. $\alpha=10^{\circ}$ and $\alpha=15^{\circ}, \beta=0^{\circ}$. 


\section{B.2 Symmetric on-flow conditions, half span, no sting}

Instead of simulating the full span configuration at symmetric on-flow conditions to obtain the integral data this data may also be reconstructed from the half span integral data. This means that the integral data of two half span configurations representing the control surface deflections of a full span configuration are added. The gain in doing so is mainly a reduction of the computing time and computing costs by a factor two, however, at the cost of possibly less accurate integral data, especially for configurations with asymmetric flap deflections.

Table 3 shows both the DLR-F19 full span integral data (FS) as well as the reconstructed full span integral data based on a series of half span simulations (HSR) at an angle of attack of $10^{\circ}$. This data was obtained using NLRs flow solver ENSOLV.

The table clearly shows that for the lift coefficient $C_{L}$, drag coefficient $C_{D}$ and pitching moment coefficient $C_{m}$, the agreement between both methods to obtain the integral data is very good. For the side force coefficient $C_{S}$, the rolling moment coefficient $C_{1}$ and the yawing moment coefficient $C_{n}$ the agreement is less satisfactory. Especially the side force coefficient $C_{S}$ shows a large discrepancy. It should, however, be noted that the absolute value of both the side force coefficient $C_{S}$ and the yawing moment coefficient $C_{m}$ are small compared to the other force and moment coefficients and are therefore more prone to computational errors. Keeping these shortcomings in mind it is clear that this approach provides a quick and reasonably accurate method for estimating the integral force and moment coefficients for symmetric on-flow conditions early on in the process of S\&C database generation.

\begin{tabular}{|c|c|c|c|c|c|c|c|c|c|c|}
\hline $\begin{array}{c}\mathrm{LOB} \\
\eta\left[^{\circ}\right]\end{array}$ & $\begin{array}{l}\text { LIB } \\
\eta\left[{ }^{\circ}\right]\end{array}$ & $\begin{array}{l}\text { RIB } \\
\eta\left[{ }^{\circ}\right]\end{array}$ & $\begin{array}{c}\text { ROB } \\
\eta\left[{ }^{\circ}\right]\end{array}$ & & $\mathrm{C}_{\mathrm{L}}$ & $C_{D}$ & $\mathrm{C}_{\mathrm{S}}$ & $\mathrm{C}_{\mathrm{m}}$ & $\mathrm{C}_{1}$ & $\mathrm{C}_{\mathrm{n}}$ \\
\hline \multirow{4}{*}{0} & \multirow{4}{*}{0} & \multirow{4}{*}{0} & \multirow{4}{*}{0} & FS & 0.1452 & 0.0330 & 0.0000 & 0.0281 & 0.0000 & 0.0000 \\
\hline & & & & HSR & 0.1452 & 0.0330 & 0.0000 & 0.0282 & 0.0000 & 0.0000 \\
\hline & & & & $\Delta$ & 0.0000 & 0.0000 & 0.0000 & -0.0001 & 0.0000 & 0.0000 \\
\hline & & & & $\Delta(\%)$ & 0.0 & 0.0 & 0.0 & 0.4 & 0.0 & 0.0 \\
\hline & & & & & & & & & & \\
\hline \multirow{4}{*}{-20} & \multirow{4}{*}{-20} & \multirow{4}{*}{0} & \multirow{4}{*}{0} & FS & 0.3615 & 0.0301 & 0.0027 & 0.0438 & -0.0334 & -0.0052 \\
\hline & & & & HSR & 0.3612 & 0.0301 & 0.0051 & 0.0439 & -0.0402 & -0.0062 \\
\hline & & & & $\Delta$ & 0.0003 & 0.0000 & -0.0024 & -0.0001 & 0.0068 & 0.0010 \\
\hline & & & & $\Delta(\%)$ & 0.1 & 0.0 & 88.9 & 0.2 & 20.4 & 19.2 \\
\hline & & & & & & & & & & \\
\hline \multirow{4}{*}{-20} & \multirow{4}{*}{-20} & \multirow{4}{*}{20} & \multirow{4}{*}{20} & FS & 0.4129 & 0.0387 & 0.0027 & 0.0283 & -0.0646 & -0.0045 \\
\hline & & & & HSR & 0.4137 & 0.0390 & 0.0071 & 0.0272 & -0.0796 & -0.0063 \\
\hline & & & & $\Delta$ & -0.0008 & -0.0003 & -0.0044 & 0.0011 & 0.0150 & 0.0018 \\
\hline & & & & $\Delta(\%)$ & 0.2 & 0.8 & 163.0 & 3.9 & 23.2 & 40.0 \\
\hline
\end{tabular}

Table 3. Integral data (at angle of attack $\alpha=10^{\circ}$ ) obtained using NLRs flow solver ENSOLV. FS indicates the DLR-F19 full span configuration integral data. HSR indicates the reconstructed full span integral data based on a series of half span simulations.

\section{B.3 Symmetric on-flow conditions, full span, with sting}

Figure 22 shows CFD results of the static aerodynamic coefficients for the BL and for the LOBLIB-RIBROB configuration in comparison to the experiment with no CS deflection. For the CS case the simulation have only been done for AoA of $\alpha=10^{\circ}$ and $\alpha=15^{\circ}$. The deflection of the control surfaces has no effect on the lift and almost no effect on the pitching moment. The rolling moment however has changed to negative values. Further to note is that the effectiveness of the CS decreases with increasing AoA.

In Figure 23 the CS case CFD results are plotted against the corresponding experimental data. It can be seen that the trend of a reduction of the rolling moment with higher AoA is predicted correctly by the simulation however the CFD results predict a reduced effectiveness compared to the experiment. The CS deflections cause an anti-clockwise turn of the configuration which is under estimated by the CFD simulation represented by a less negative rolling moment. 


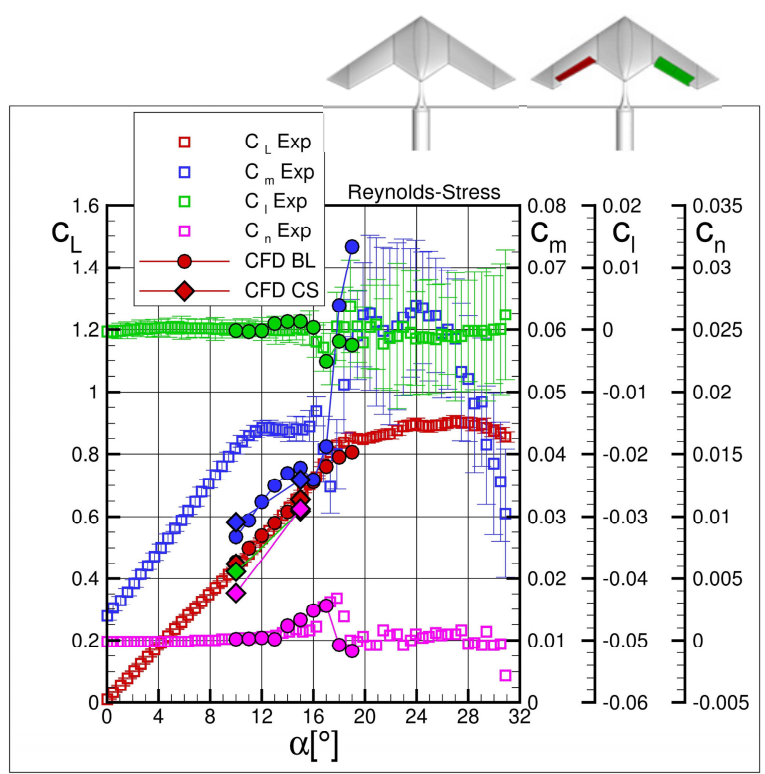

Figure 22. CFD prediction in comparison to the experiment using the RSM: Lift, drag, pitching and rolling moment coefficient. Effect in rolling moment without and with CS deflection. CFD: $\alpha=10^{\circ}$ and $15^{\circ}, \beta=0^{\circ}$.

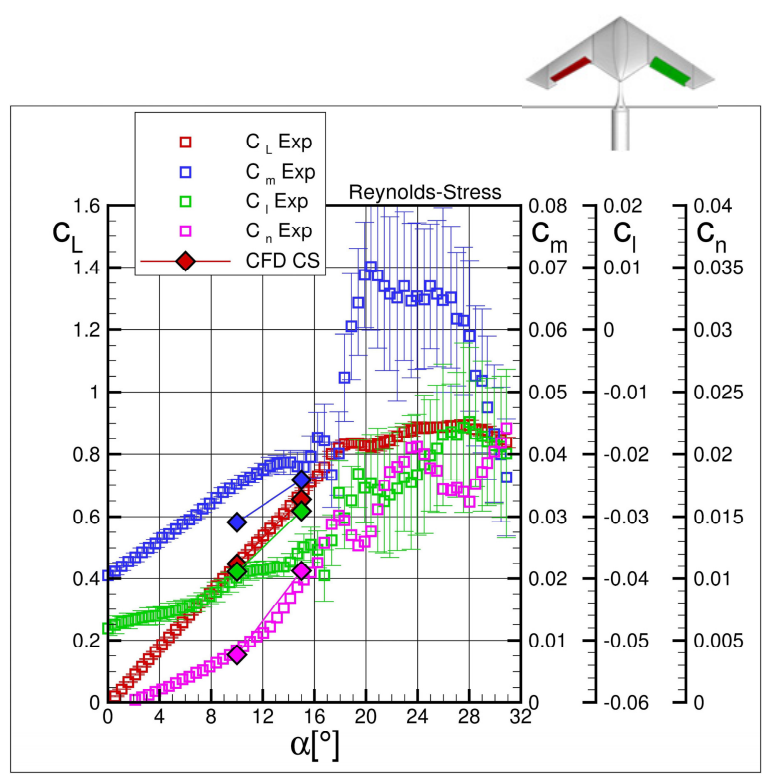

Figure 23. CFD prediction in comparison to the experiment using the RSM: Lift, pitch, roll and yaw moment coefficient. CS (LOBLIB-RIBROB). CFD: $\alpha=10^{\circ}$ and $15^{\circ}, \beta=0^{\circ}$.
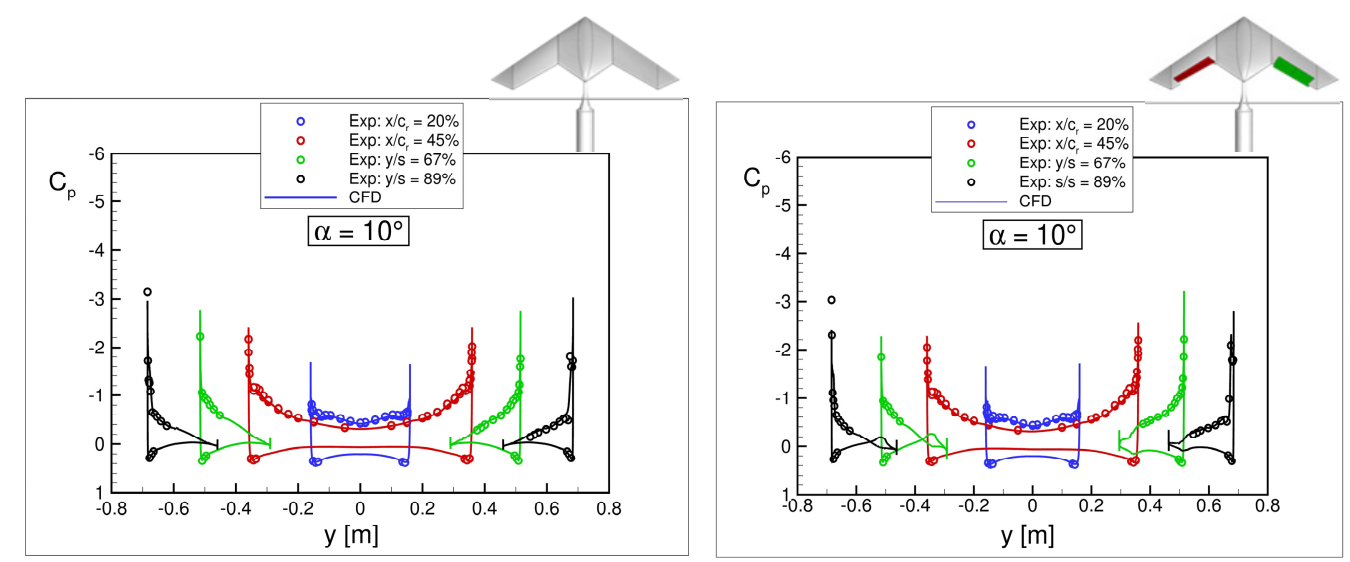

Figure 24. Comparison of the surface pressure distribution between CFD and experiment at four different $\mathrm{x}=$ const. locations: $\mathrm{BL}$ and CS (LOBLIB-RIBROB) configuration, $\alpha=10^{\circ}$, RSM.

Figure 24 and Figure 25 show the experimental and simulated surface pressure distribution on the upper surface of the configuration without and with CS deflection at AoA of $\alpha=10^{\circ}$ and $15^{\circ}$. For both cases the simulation fits quite well with the experiment, except for the flow physics in the wing tip area for $\alpha=15^{\circ}$. It's interesting to point that even for the BL configuration small asymmetries occur. These asymmetries are also represented by the CFD simulations shown in Figure 22 indicated by the asymmetries in the rolling moment $c_{1}$. 

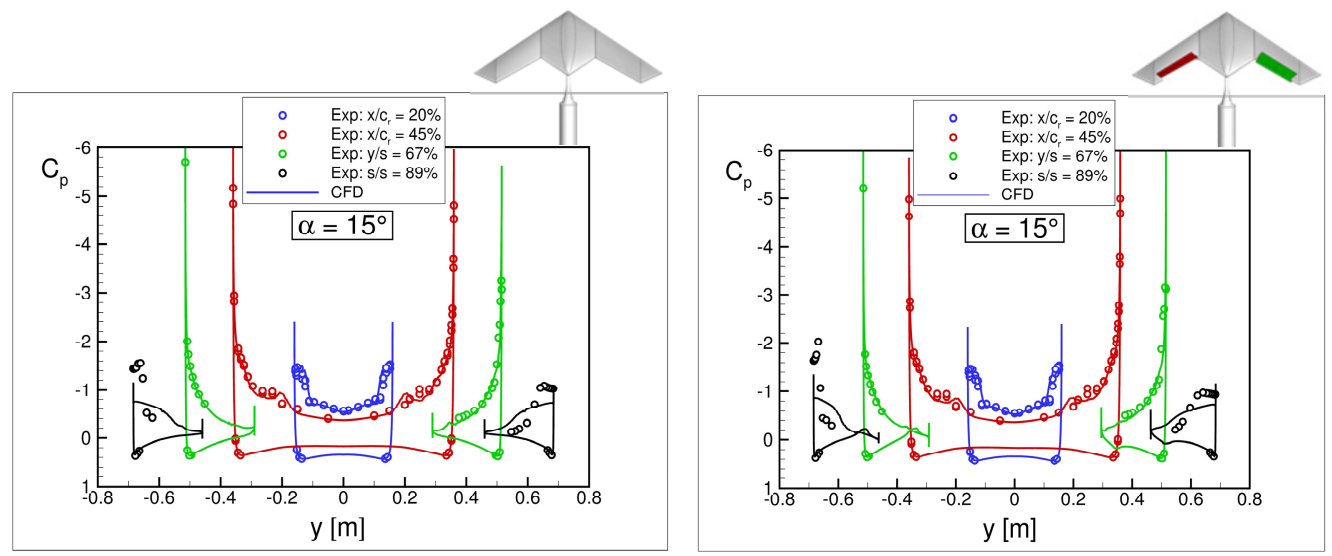

Figure 25. Comparison of the surface pressure distribution between $\mathrm{CFD}$ and experiment at four different $\mathrm{x}=$ const. locations: BL and CS (LOBLIB-RIBROB) configuration, $\alpha=15^{\circ}$, RSM.

If we have a look at the flow topology in the Figure 26 and Figure 27 it can be seen that the tip vortex is not interacting directly with the flow over the control surfaces. The incorrectly predicted tip vortex flow has probably more effect on the pitching moment than the flow over the control surfaces. This is indicated by the pressure distribution in Figure 25 on the right hand side and the tip flow topology in Figure 27 for $\alpha=15^{\circ}$ (LOBLIBRIBROB).
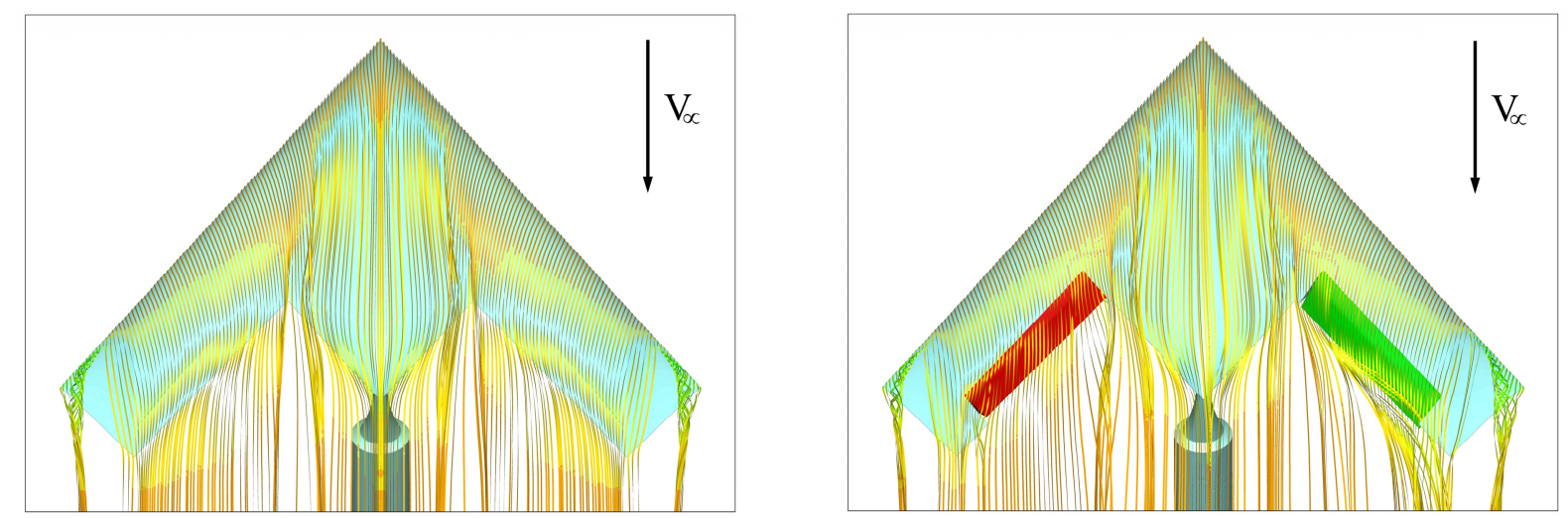

Figure 26. DLR TAU-Code: Flow Topology on the upper side of the DLR-F19 BL and LOBLIB-RIBROB configuration: $\alpha=10^{\circ}$, RSM.

The suction peaks of the tip vortices in both cases are too low as seen in Figure 24 and Figure 25. This causes a reduced load in the wing tip area and thus a more rear loading pitching moment. With respect to the flow topology this means that the tip vortcies in Figure 27 for $\alpha=15^{\circ}$ are predicted too far upstream and an onset of vortex breakdown already occurs.

The flow over the control devices is significantly different between the two AoAs. For $\alpha=10^{\circ}$ the flow over the control devices is attached. The vortex from the apex is passing the control devices inboard. For $\alpha=15^{\circ}$ the apex vortex is bigger and is effecting the control devices inboard. The flow over the CS is dominated by vortical flow of the separated flow of the former attached flow area between the apex and the tip vortex. The streamlines interacting with the CS are more or less parallel to the hinch line or trailing edge respectively. This is reducing the dynamic pressure facing the CS and thus the effectiveness of the control surfaces. 

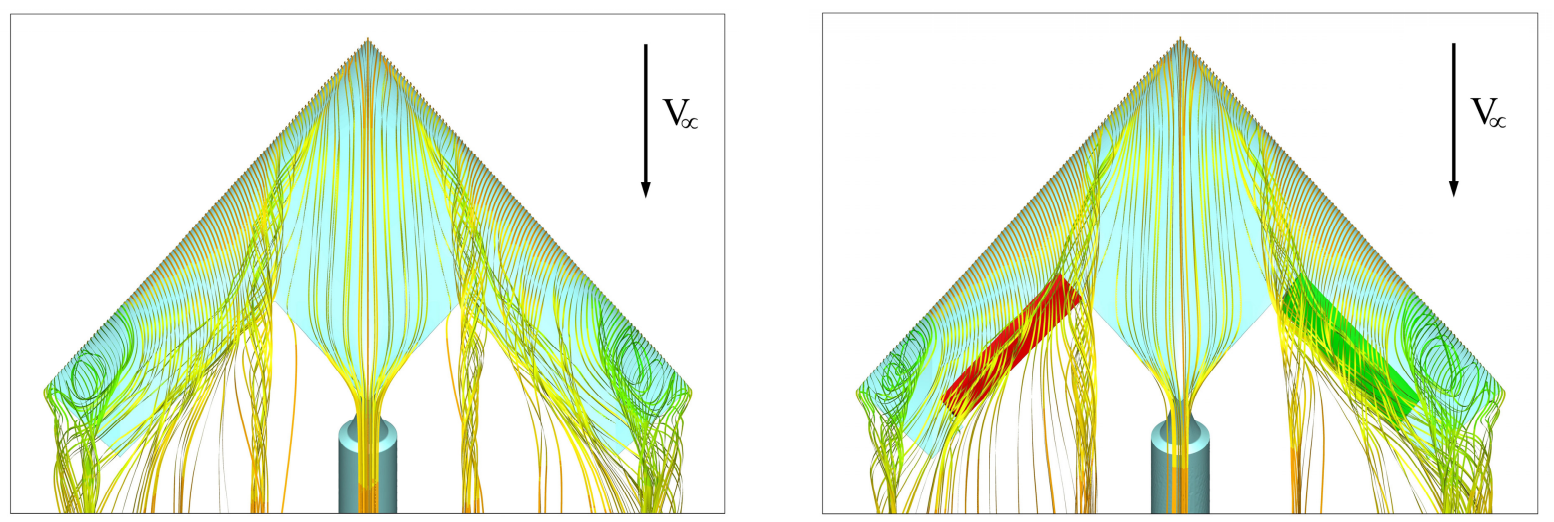

Figure 27. DLR TAU-Code: Flow Topology on the upper side of the DLR-F19 BL and LOBLIB-RIBROB configuration: $\alpha=15^{\circ}$, RSM.

\section{Asymmetric on-flow conditions}

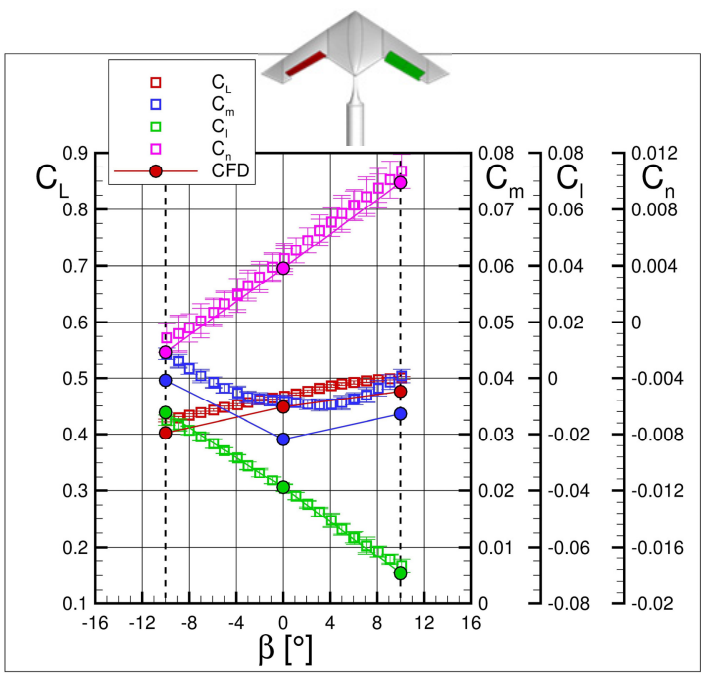

In this section the prediction capability and flow physics regarding asymmetric flow conditions will be discussed. Figure 28 shows for the LOBLIB-RIBROB configuration the lift, pitching, rolling and yawing moment coefficient at an AOA $\alpha=10^{\circ}$ for three different angles of side slip $\beta=-10^{\circ}$, $0^{\circ}$ and $10^{\circ}$ in comparison to the experiment. It can be observed that the overall trend of the aerodynamic coefficients is predicted quite well by CFD in comparison to the experimental data. The pitching moment is under predicted which have been already observed in the results for the BL configuration. In Figure 29 the surface pressure distribution is plotted for $\beta=-10^{\circ}$ and $10^{\circ}$. For both AoS the pressure distribution predicted by CFD matches the experimental data very well.

Figure 28. CFD prediction in comparison to the experiment: Lift, pitching, rolling and yawing moment coefficient $\alpha=10^{\circ}, \beta=10^{\circ}$ and $-10^{\circ}$. CFD: RSM.
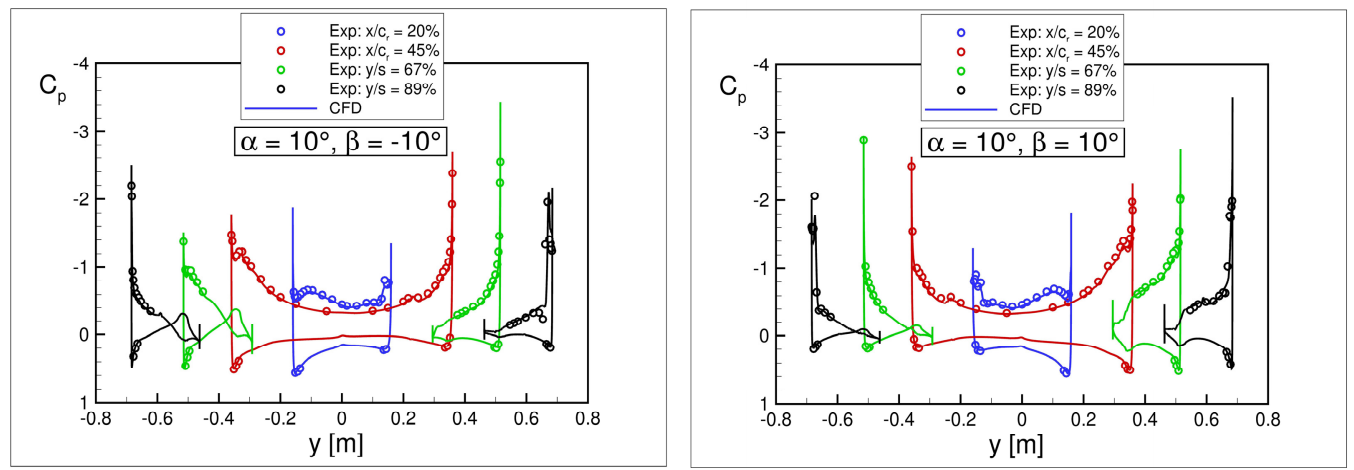

Figure 29. Comparison of the surface pressure distribution between CFD and experiment at four different $\mathrm{x}=$ const. locations: LOBLIB-RIBROB $, \alpha=10^{\circ}, \beta=-10^{\circ}$ and $10^{\circ}$, RSM. 
Figure 30 and Figure 31 show the flow topology for both $\beta=-10^{\circ}$ and $10^{\circ}$. In comparison to the symmetric flow conditions in Figure 26 the apex vortex on the windward side of the wing is vanished due to the reduced induced sweep angle. On the leeward side the structure of the apex vortex is stronger than in the symmetric case. Comparing the two AoS cases with each other there is not much difference in the pressure level even though the flow on the leeward side for $\beta=-10^{\circ}$ gets accelerated by the downward flap deflection in opposition to the $\beta=10^{\circ}$ case where the flow gets decelerated.

Overall the CFD simulation represents the experiments very well with respect to the integral values and the pressure distribution.

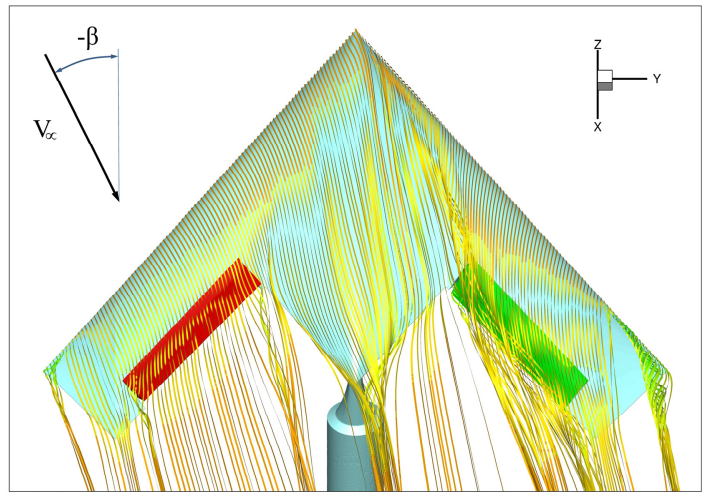

Figure 30. DLR TAU-Code: Flow Topology on the upper side of the DLR-F19 configuration. $\alpha=10^{\circ}, \beta=$ $10^{\circ}$, RSM.

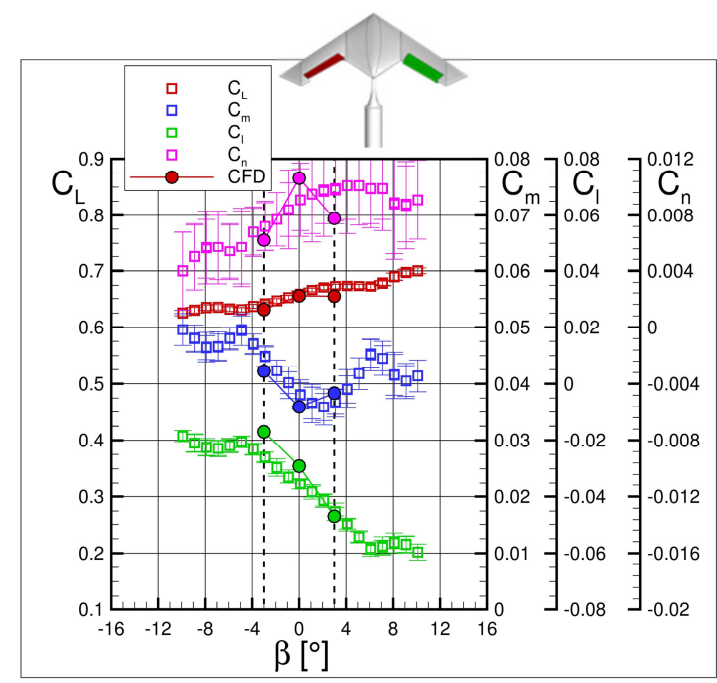

Figure 32. CFD prediction in comparison to the experiment: Lift, pitching, rolling and yawing moment coefficient $\alpha=14.7^{\circ}, \beta=-3^{\circ}, 0^{\circ}$ and $3^{\circ} \mathrm{CFD}$ : RSM.

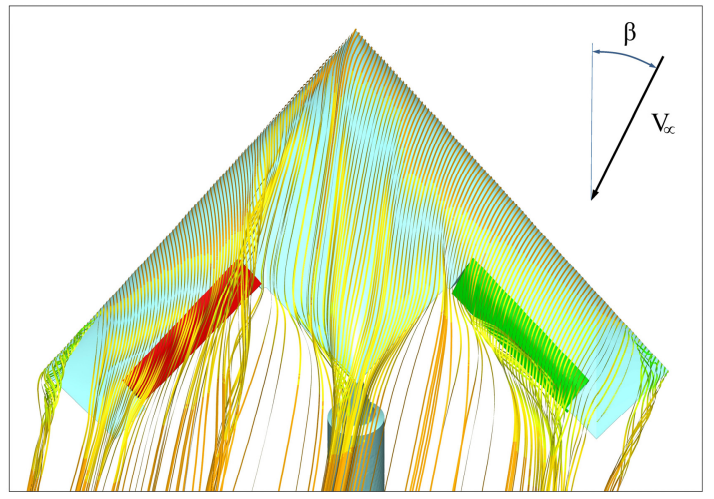

Figure 31.DLR TAU-Code: Flow Topology on the upper side of the DLR-F19 configuration. $\alpha=10^{\circ}, \beta=10^{\circ}$, RSM.

Figure 32 shows the CFD results of the LOBLIBRIBROB configuration in comparison to the experiment for an AOA of $\alpha=14.7^{\circ}$ and $\operatorname{AoS}$ of $\beta=-3^{\circ}, 0^{\circ}$ and $3^{\circ}$. As for the previous cases the overall trend of the aerodynamic coefficients is predicted quite well by CFD in comparison to the experimental data. It can be seen that the rolling moment is slightly overestimated by the CFD simulations for $\beta=-3^{\circ}$, $0^{\circ}$. The lift and pitching moment is predicted quite well in comparison to the experimental data. The magnitude of the yawing moment is very small and is considered as not much relevant for this case.

Figure 33 shows the corresponding estimated pressure distributions in comparison to the experiment for $\beta=-3^{\circ}$ and $3^{\circ}$. For both AoS the pressure distribution is predicted in the front part correctly. The suction peaks of the tip vortex are on the left hand side slightly underestimated for both AoS.

Finally, in Figure 34 the flow topology for the two AoS is depicted. As already described in the previous example the apex vortex on the leeward side of the wing is stronger than on the windward side. Although the AoS is quite small the effect is relevant for the present AoA with respect to the roll stability. A positive side slip causes a negative stabilizing rolling moment. The AoS is small enough that the apex vortex is not vanished on the windward side of the wing in comparison to the previous case at an $\operatorname{AoS}$ of $\beta= \pm 10^{\circ}$. 

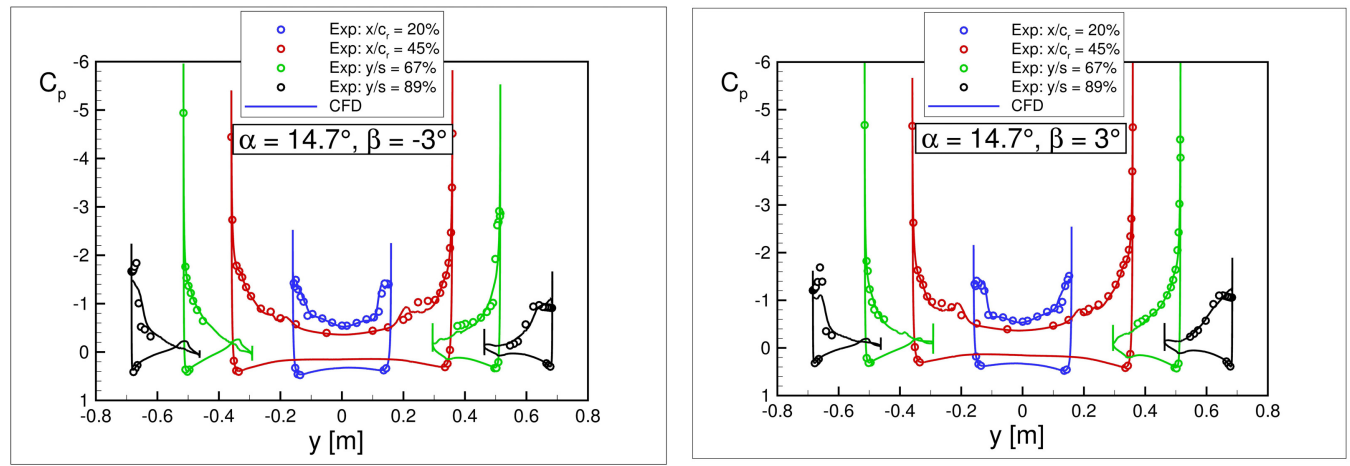

Figure 33. Comparison of the surface pressure distribution between CFD and experiment at four different $x=$ const. locations: LOBLIB-RIBROB, $\alpha=14.7^{\circ}, \beta=-3^{\circ}$ and $3^{\circ}$, RSM.
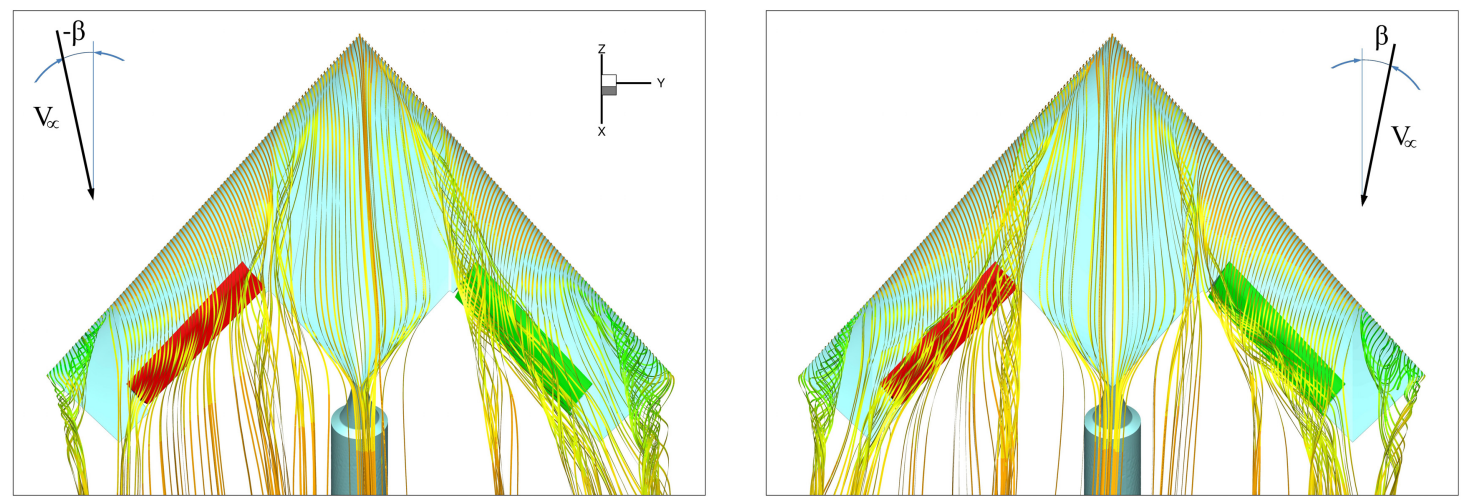

Figure 34. DLR TAU-Code: Flow Topology on the upper side of the DLR-F19 configuration. $\alpha=14.7^{\circ}, \beta=-3^{\circ}$ and $3^{\circ}$, RSM.

In the previous figures Figure 28 and Figure 32 the prediction capabilities have been discussed comparing CFD simulations taking the sting into account in comparison with the experiment. As discussed before one uncertainty is the prediction of the flow around the sting support. The support influences the prediction accuracy of the integral aerodynamic coefficients. If the wake flow and resulting pressure distribution on the lower side of the wing is not predicted correctly it might have significant influence on the prediction of the pitching moment.

In Figure 35 and Figure 36 the differences of the $\mathrm{S} \& \mathrm{C}$ values between the configuration with and without control device deflection are plotted against each other. It can be observed that the values of the differences in lift, pitching and yawing moment can be predicted sufficiently. The differences in the rolling moment are in a similar range although for the case at $\alpha=10^{\circ}$ and $\beta= \pm 3^{\circ}$ the trend is not represented correctly.

In Figure 37 and Figure 38 the same values are plotted as in the Figure 35 and Figure 36 with the difference that now the sting support was not taken into account in the CFD simulations. The idea was using CFD simulations without sting might enhance the match between CFD and experiment. Hence it would reduce the computational effort by leaving out the sting support. Looking at the plot in Figure 37 for $\alpha=10^{\circ}$ and $\beta= \pm 10^{\circ}$ almost no difference appears between both approaches. The differences in lift, rolling- and yawing moment are the same as in Figure 35. The pitching moment differences are slightly higher in the case without sting in Figure 37 . Almost the same applies for the case in Figure 38 for $\alpha=14.7^{\circ}, \beta=-3^{\circ}$ and $3^{\circ}$ and Figure 36 respectively. For this case the differences in the CFD simulations in the rolling moment are higher than for the case where no sting support is taken into account.

It seems to be that the sting support has slightly more influence on the overall flow physics than just on the flow around the lower rear part of the configuration. Hence, the differentials are not just neglecting the sting effect. 


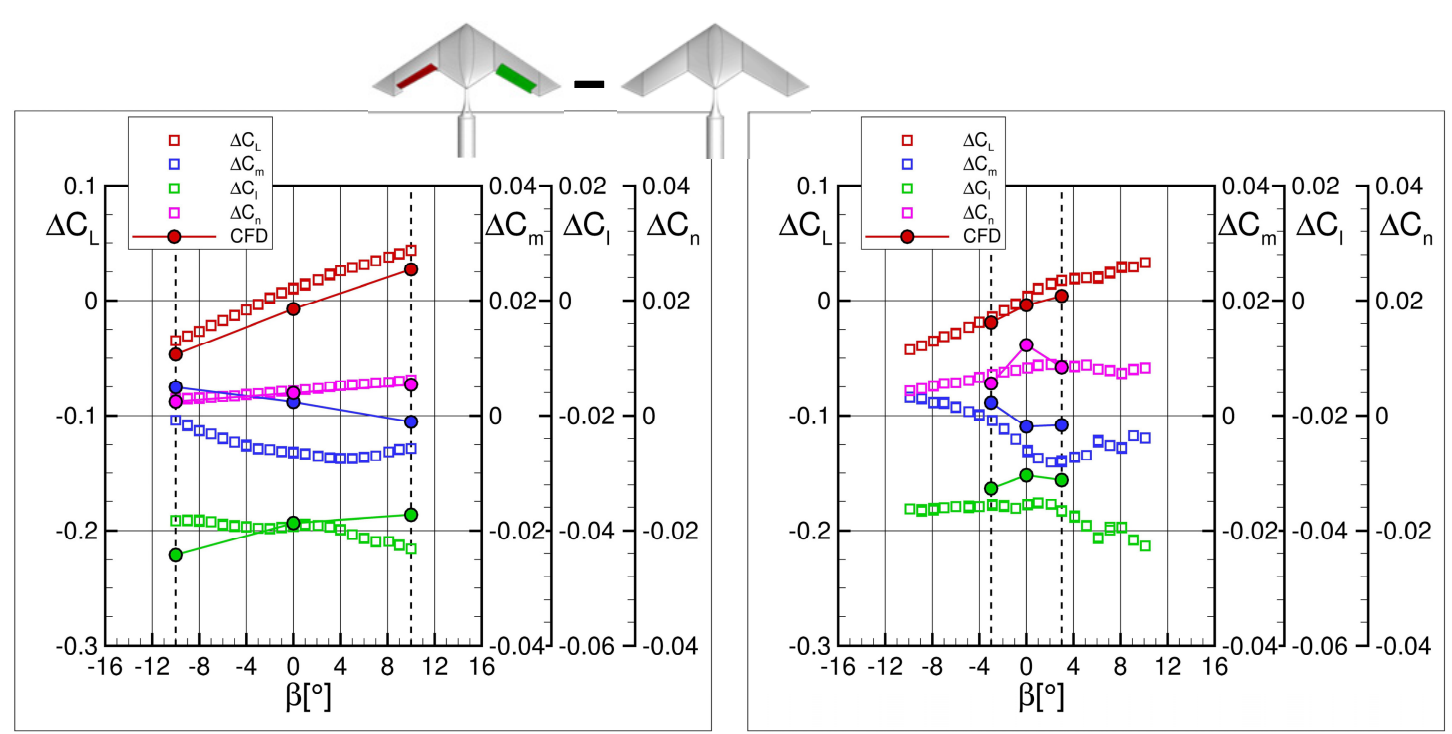

Figure 35. Differences in lift, pitching, rolling and yawing moment versus AoS between the LOBLIBRIBROB and BL configuration. CFD: $\alpha=10^{\circ}, \beta=-10^{\circ}$ and $10^{\circ}, \mathrm{RSM}$ (with sting support).
Figure 36. Differences in lift, pitching, rolling and yawing moment versus AoS between the LOBLIBRIBROB and BL configuration. CFD: $\alpha=14.7^{\circ}$, $\beta=-3^{\circ}$ and $3^{\circ}$, RSM (with sting support).

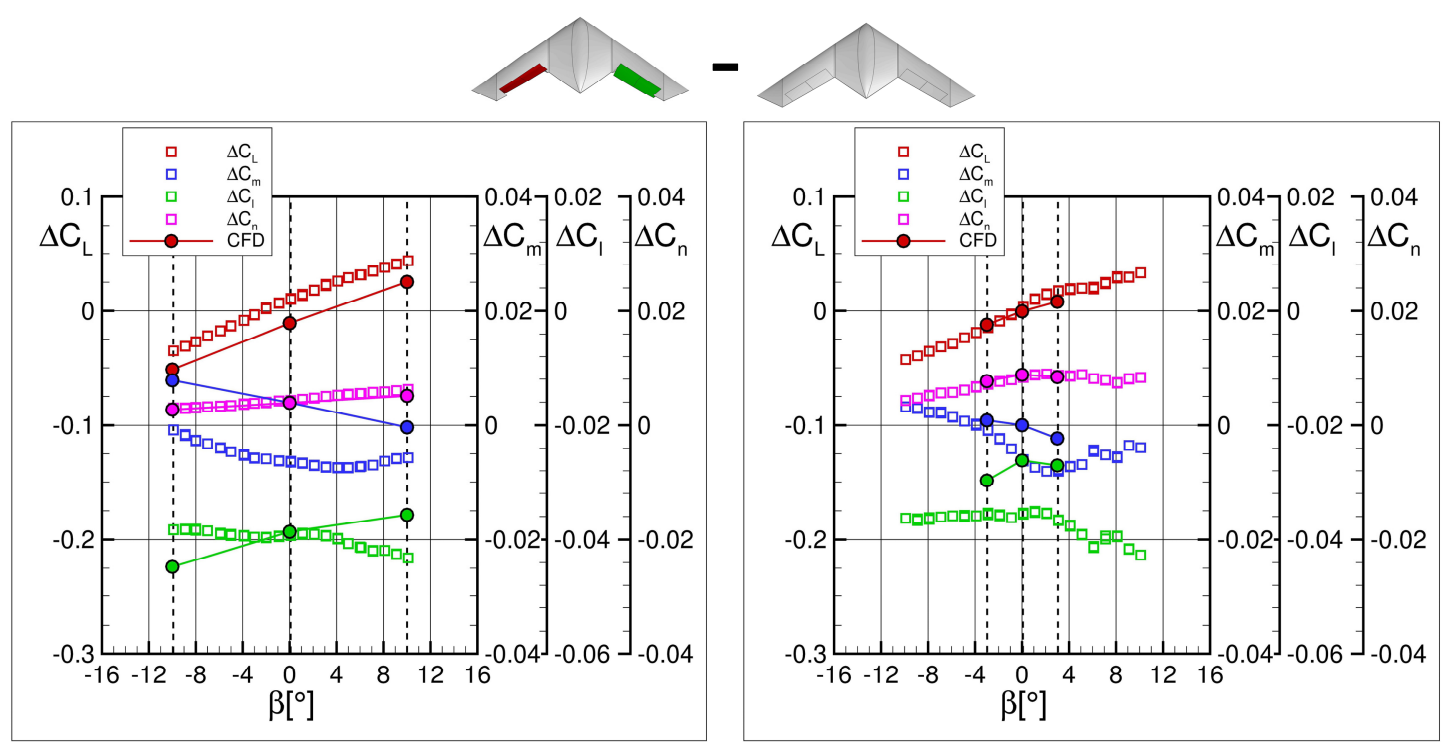

Figure 37. Differences in lift, pitching, rolling and yawing moment versus AoS between the LOBLIBRIBROB and BL configuration. CFD: $\alpha=10^{\circ}, \beta=-10^{\circ}$ and $10^{\circ}$, RSM (no sting support).

Figure 38. Differences in lift, pitching, rolling and yawing moment versus AoS between the LOBLIBRIBROB and BL configuration. CFD: $\alpha=14.7^{\circ}, \beta=-3^{\circ}$ and $3^{\circ}$, RSM (no sting support). 


\section{Dynamic Simulations}

In this section the dynamic aerodynamic behavior will be discussed. The pitching motion of the BL and LOBLIB-RIBROB configuration in comparison to the experiment will be taken as an example to evaluate the dynamic prediction capability for low and medium range AoA.

For both simulations the motion frequency is $2 \mathrm{~Hz}$ and the model is pitching around an AoA of $\theta_{0}=10^{\circ}$ with an amplitude of $\Delta \theta=5^{\circ}$. The model is pitching around an axis at $84 \%$ inner chord which is $24 \%$ behind the MRP.

In Figure 39 the numerical results in comparison to the experiment are shown for $\theta=14^{\circ}$ with increasing and decreasing AoA motion. On the left hand side the CFD simulated pressure distributions are plotted in comparison to the experiment. For both upward and downward types of motion no significant difference can be observed. The comparison of the curves between the simulation and the experiment shows no difference in the normal force coefficient. Looking at the pitching moment differences can be observed very well. The normal force shows no hysteresis effects and both curve gradients are the same. The pitching moment on the other hand shows a hysteresis where both the shape and gradient of the hysteresis curve are different between the CFD simulation and the experiment. Nevertheless, the deltas in absolute values for both types of motion on the hysteresis for $\theta=14^{\circ}$ are comparable to the deltas which have been observed in the steady state simulations.

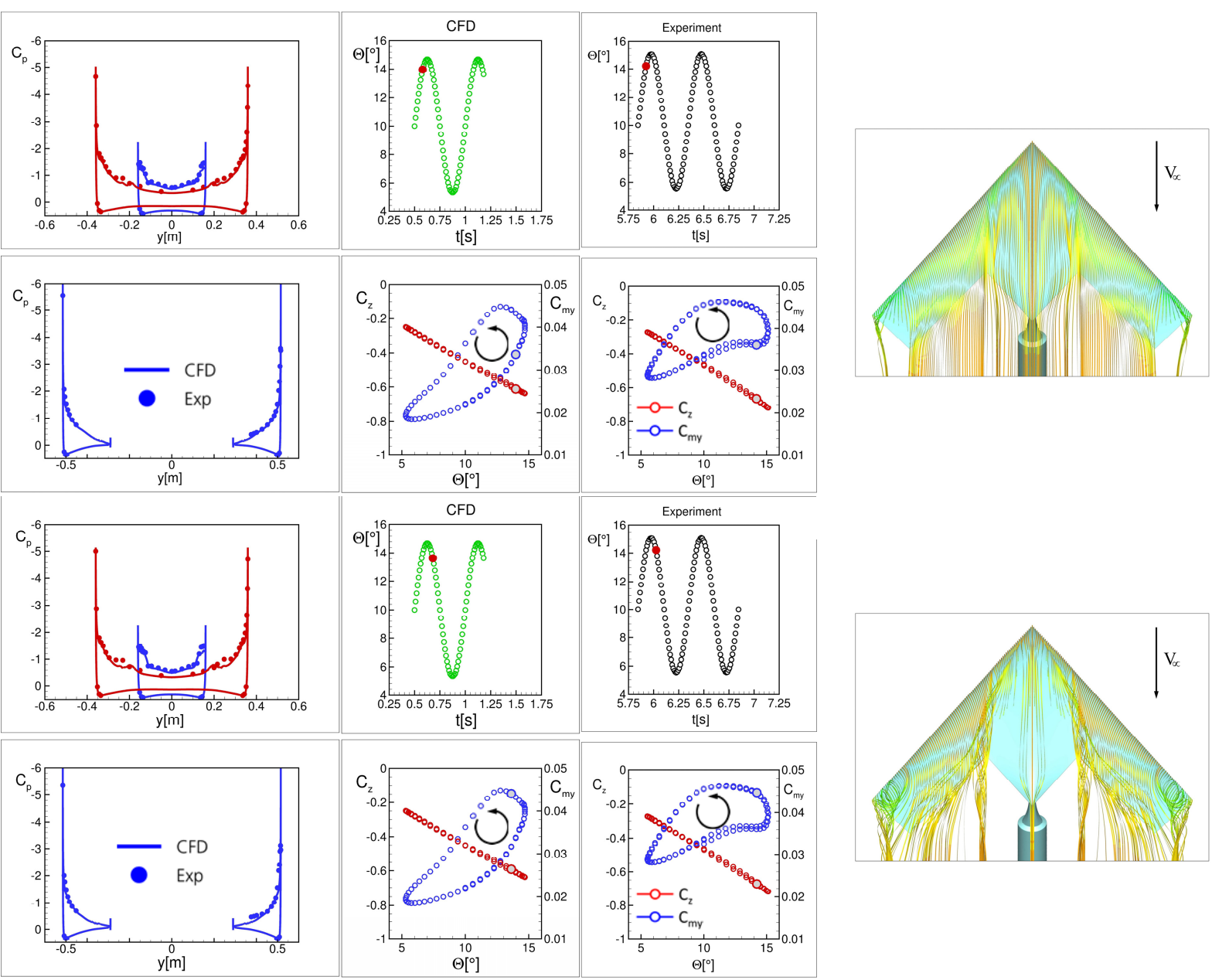

Figure 39. Pitching motion: $\theta_{0}=10^{\circ}, \Delta \theta=5^{\circ}, \mathrm{f}=2 \mathrm{~Hz}$; CFD in comparison to the Experiment (BL configuration). Upper figures upward motion; lower figures downward motion.

On the right hand side the simulated streamlines for both motions on the hysteresis for $\theta=14^{\circ}$ are depicted. It can be observed that the topology of the vortex structure over the wing is the same but for the downward motion the apex vortex tends to be stronger and the tip vortex weaker due to the onset of vortex breakdown. This slight difference can also be observed for the apex vortex comparing the pressure distribution for upward and 
downward motion. This causes a more positive rear loading pitching moment for the downward motion than for the upward one. The difference is small but the pitching moment is very sensitive due to the position of the MRP as discussed before.

In Figure 40 the results for $\theta=10^{\circ}$ for the upward and downward motion are depicted. For $\theta=10^{\circ}$ the same effect occur as previously discussed for $\theta=14^{\circ}$.

Overall it can be observed that the dynamic pressure distribution over the wing and the trajectory of the normal force can be predicted quite well by the numerical simulation. However, the shape and gradient of the pitching moment hysteresis is predicted differently, but the incremental differences at various pitch angles are comparable to the differences observed for the steady state solutions.

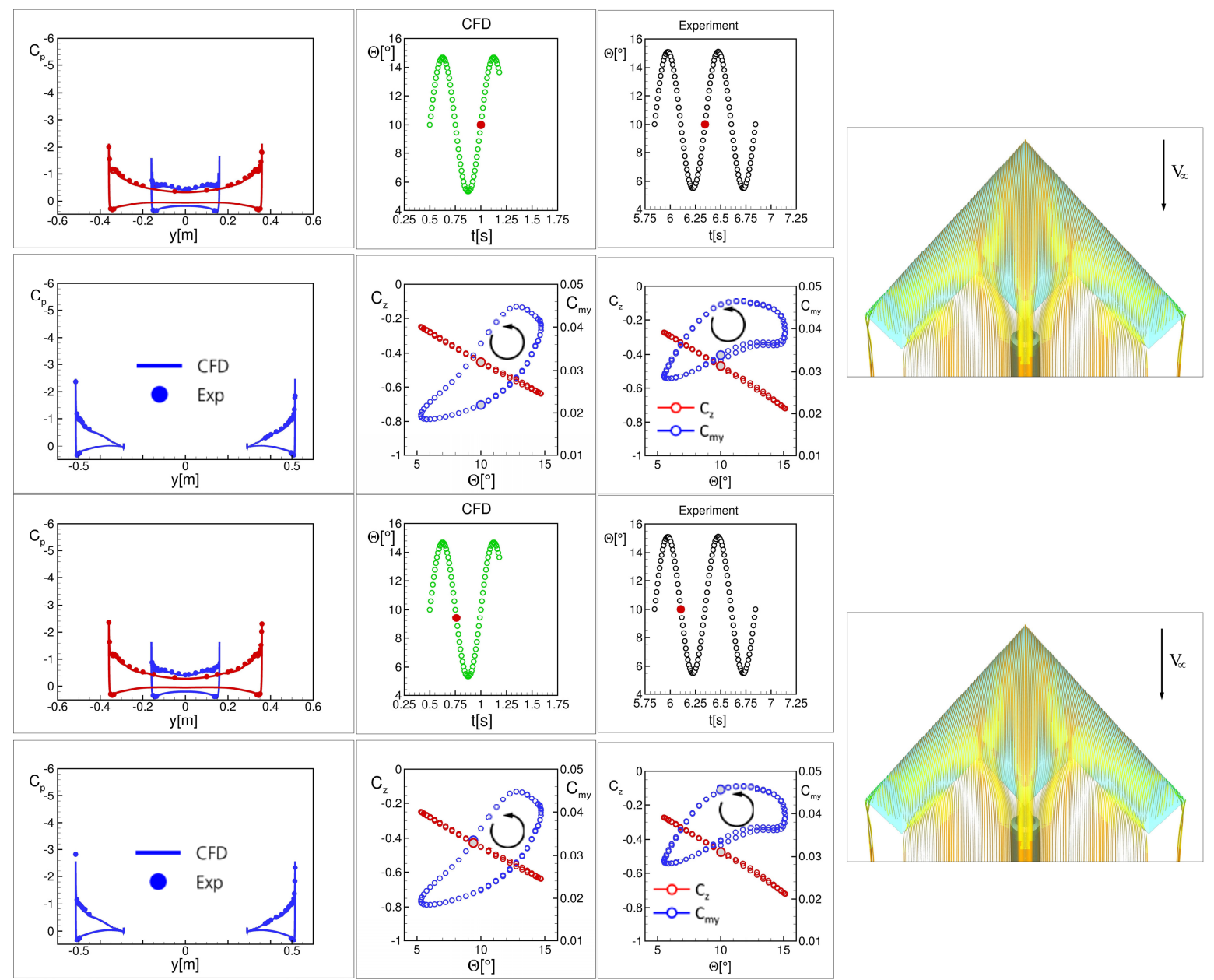

Figure 40. Pitching motion: $\theta_{0}=10^{\circ}, \Delta \theta=5^{\circ}, \mathrm{f}=2 \mathrm{~Hz}$; CFD in comparison to the Experiment (BL configuration). Upper figures upward motion; lower figures downward motion.

Figure 41 shows the results of the corresponding pitching maneuver of the LOBLIB-RIBROB configuration. As an example the case for an AoA $\theta=10^{\circ}$ should be discussed for the upward and downward motion. As for the BL configuration the simulated surface pressure distributions matches the experimental data very well.

With respect to the normal force it can be observed that there is again no difference between the CFD simulations in comparison to the experiment in the same way as for the BL configuration. For the pitching moment there is a significant hysteresis loop which matches much better with the experimental data for the present CS case than before for the BL configuration. This applies for the thickness of the loop and for the gradient too.

On the right hand side of the Figure 41 the flow topology on the upper side of the wing is depicted. For the upward motion at $\theta=10^{\circ}$ we have again more or less fully attached flow with a small apex vortex and a small vortical flow separation at the wing tips. For the downward motion the apex vortex is as well much stronger than the 
tip vortices in comparison to the upward motion. In comparison to the BL configuration the location of the apex vortex on the left hand side is a little bit more inboard and the one on the right hand side a bit more outboard due to the control surface deflections.

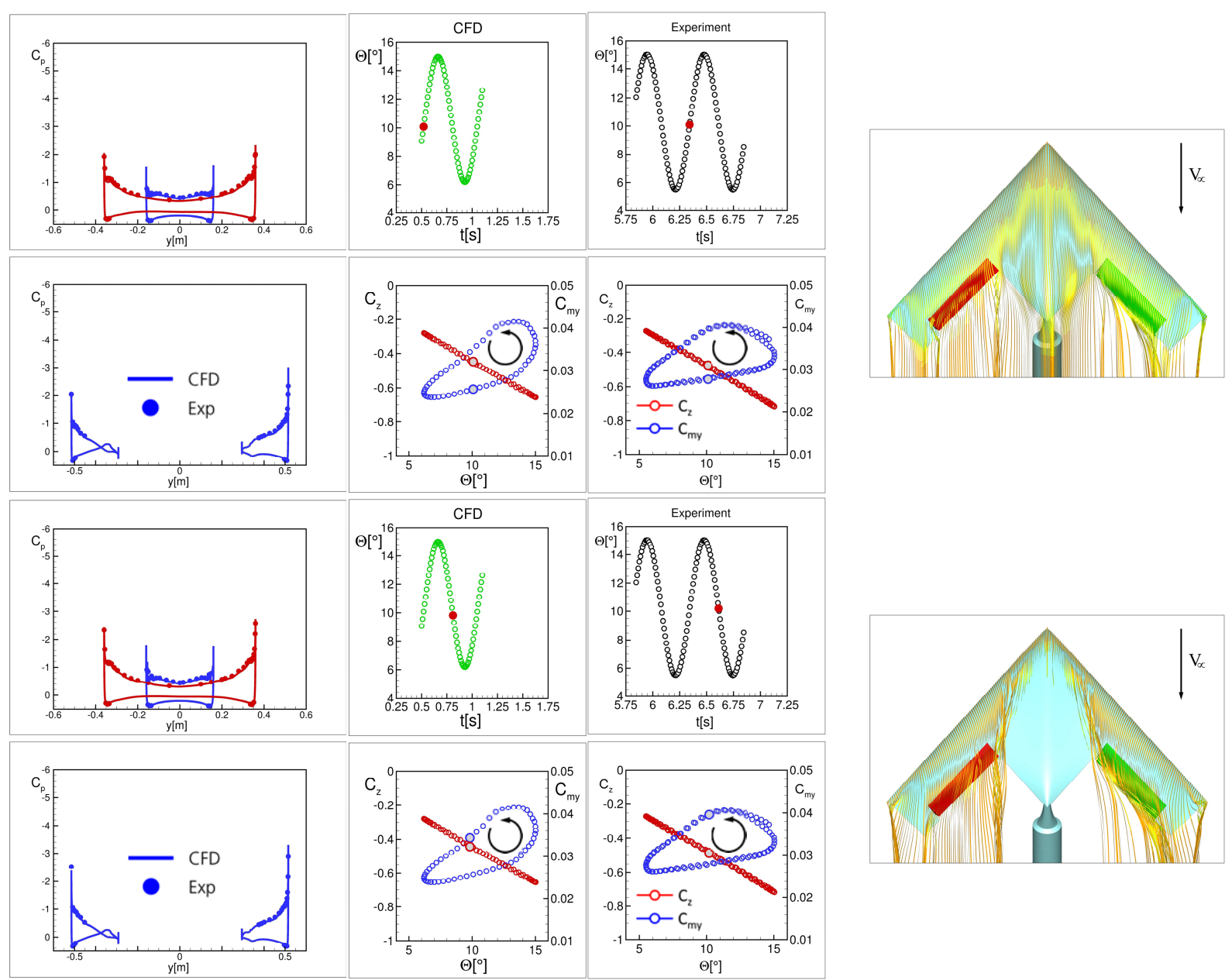

Figure 41. Pitching motion: $\theta_{0}=10^{\circ}, \Delta \theta=5^{\circ}, \mathrm{f}=2 \mathrm{~Hz}$; CFD in comparison to the Experiment (LOBLIB-RIBROB configuration). Upper figures upward motion; lower figures downward motion.

Both test cases without and with control surface deflection show a pretty good match of the dynamic behavior in comparison to the experimental data. There is a difference in the shape of the hysteresis loop of the pitching moment for both configurations and as well in the gradient of the loop for the BL configuration. Both pitching moment curves show significant non-linearities which have been already discussed regarding the steady state solution. An assessment how relevant the differences are for $\mathrm{S} \& \mathrm{C}$ estimations have to be done by substituting experimental by CFD data sets in the flight mechanics model. The differences comparing the system answer of the experimental based with the CFD based flight mechanics model is expected to be small in the linear regime. In the non-linear regime this might be not the case regarding the results presented in this paper. The assessment if the differences in the non-linear regime are acceptable for S\&C predictions will be evaluated in the Task Group in the near future 


\section{Conclusion}

In this paper the prediction capabilities with high fidelity CFD methods of the flow field and static and dynamic aerodynamic behavior of a generic $53^{\circ}$ swept lambda wing configuration (DLR-F19) with and without trailing edge control surfaces have been shown. To this end simulations have been done using the unstructured grid based DLR TAU-Code and the structured (multi-block) grid based NLR solver ENSOLV. The simulation results have been compared among each other as well as to the available experimental data. Model configurations with and without control surface deflections have been evaluated as well as the effect of the model support. These comparisons lead to the following conclusions:

Both state-of-the-art CFD methods are well capable of predicting the dominant flow features on the DLR-F19 configuration. The agreement between both methods is good.

To simulate the flow features at higher angles of attack realistically, i.e. $\alpha$ greater than $15^{\circ}$, more advanced turbulence models, such as the RSM turbulence model, are required. For angles of attack $\alpha$ smaller than $15^{\circ}$, more conventional turbulence models are sufficient, especially when these simulations are used for S\&C database generation.

For symmetric on-flow conditions (AoS equals $0^{\circ}$ ) and low AoA the $\mathrm{S} \& \mathrm{C}$ database for the full span configuration may well be reconstructed from the half span integral data. This is applicable for the BL as well as for configuration with control surface deflections. This will reduce the computing time and costs by a factor two.

For an accurate comparison with wind tunnel data the modelling of the belly sting support is essential, since it was found that the sting support not only gives rises to an unsteady wake on the lower side of the configuration, but also has an effect on the flow on the upper side of the configuration.

First results of dynamic simulations, showing a fairly good agreement with the experimental data, have been presented. Future research will, in addition to better understanding and modelling the flow physics, focus more on such simulations and how they can efficiently be used to generate an S\&C database.

\section{Acknowledgments}

The authors would like to thank the whole team from DLR and DNW-NWB wind tunnel in Braunschweig for gathering the data with the DLR-F19 model configuration.

Furthermore, we would like to thank all the members of NATO STO AVT-201 Task Group on "Extended Assessment of Stability and Control Prediction Methods for NATO Air Vehicles" for their support and collaborative work within the NATO STO/AVT research community.

The authors from DLR would like to thank the German MoD and The Federal Office of Bundeswehr Equipment, Information Technology and In-Service Support (BAAINBw) for their support for the military research at DLR and the support to attend the NATO STO/AVT Task Group meetings.

Part of this work has been conducted under programmatic research funding "Kennis voor Beleid en Toepassing" of the NLR.

\section{References}

${ }^{1}$ Hummel, D., and Redeker, G., "A new vortex flow experiment for computer code validation,” In: RTO AVT Symposium on Vortex Flow and High Angle of Attack Aerodynamics, Loen, Norway, 7-11 May 2001, Meeting Proceedings RTO-MP-069 (I), pp. 8-1 to 8-31 (2003).

${ }^{2}$ Hummel, D., "The second international vortex flow experiment (VFE-2): Objectives and first results," 2nd International Symposium on "Integrating CFD and Experiments in Aerodynamics", 5 - 6 September 2005, Cranfield University, UK. J. of Aerospace Engineering, Vol. 220 (2006), Nr. 6: 559 - 568.

${ }^{3}$ Hummel, D., "Review of the Second International Vortex Flow Experiment (VFE-2)," AIAA Paper 2008-377, 46th AIAA Aerospace Sciences Meeting and Exhibit, Reno, Nevada, Jan. 7-10, 2008.

${ }^{4}$ Schütte, A., and Lüdeke, H., "Numerical investigations on the VFE-2 65-Degree rounded leading edge delta wing using the unstructured DLR-TAU-Code," Journal of Aerospace Science and Technology (AST), Volume 24, Issue 1, January-February 2013, Pages 56-65.

${ }^{5}$ Fritz, W., and Cummings, R. M., "What was Learned from the Numerical Simulations for the VFE-2," AIAAPaper 2008-399, 46th AIAA Aerospace Sciences Meeting and Exhibit, 2008, 10.2514/6.2008-399.

${ }^{6}$ Luckring, J.M., and Hummel, D., "What was learned from the new VFE-2 experiments?" AIAA Paper 20080383, 46th AIAA Aerospace Sciences Meeting and Exhibit, 2008, 10.2514/6.2008-383. 
${ }^{7}$ Hummel, D., and Lamar, J. et al., "Understanding and Modeling Vortical Flows to Improve the Technology Readiness Level for Military Aircraft,“ NATO RTO/AVT, Final report of the AVT-113 Task Group, RTO-TRAVT-113 AC/323(AVT-080)TP/253, Oct. 2009.

${ }^{8}$ Boelens, O.J., Babcock, K.J., Elmilgui, A., Abdol-Hamid, K.S., and Massey, S.J., "Comparison of Measured and Block Structured Simulation Results for the F-16XL Aircraft," Journal of Aircraft, 2009, Vol.46: 377-384, $10.2514 / 1.35064$.

${ }^{9}$ Görtz, S., Jirásek, A., Morton, S.A., McDaniel, D.R., Cummings, R.M., Lamar, J.E., and Abdol-Hamid, K.S., "Standard Unstructured Grid Solutions for Cranked Arrow Wing Aerodynamics Project International F-16XL," Journal of Aircraft, 2009, Vol.46: 385-408, 10.2514/1.35163.

${ }^{10}$ Fritz, W., Davis, M.B., Karman, S.L., and Michal, T., "Reynolds-Averaged Navier-Stokes Solutions for the CAWAPI F-16XL Using Different Hybrid Grids,” Journal of Aircraft, 2009, Vol.46: 409-422, 10.2514/1.35106.

${ }^{11}$ Schütte, A., Boelens, Okko J., Oehlke, M., Jirásek, A., and Loeser, T., "Prediction of the flow around the X-31 aircraft using three different CFD methods," Journal of Aerospace Science and Technology, Volume 20, Issue 1, July - August, 2012, p. 21-37. ISSN 1270-9638, 10.1016/j.ast.2011.07.014.X-31.

${ }^{12}$ Vicroy, D.D., Loeser, Thomas D., and Schütte A.," Static and Forced-Oscillation Tests of a Generic Unmanned Combat Air Vehicle," Journal of Aircraft, Vol. 49, No. 6 (2012), pp. 1558-1583. doi: 10.2514/1.C031501

${ }^{13}$ Roosenboom, E.W.M., Konrath, R., Schröder, A., Pallek, D., Otter, D., Morgand, S., Gilliot, A., Monnier, J. C., Le Roy, J.F., Geiler, C., Pruvost J., "Stereoscopic Particle Image Velocimetry Flowfield Investigation of an Unmanned Combat Air Vehicle,“ Journal of Aircraft, 2012, Vol.49: 1584-1596, 10.2514/1.C031587.

${ }^{14}$ Cummings, R.M. and Schuette A.," Integrated Computational/Experimental Approach to Unmanned Combat Air Vehicle Stability and Control Estimation," Journal of Aircraft, Vol. 49, No. 6 (2012), pp. 1542-1557. doi: 10.2514/1.C031430

${ }^{15}$ Cummings, R.M. and Schuette A. et al., "Assessment of Stability and Control Prediction Methods for NATO Air and Sea Vehicles," NATO RTO/AVT, Final Report of the AVT-161 Task Group, RTO-TR-AVT-161 AC/323(AVT-161)TP/440, Sept. 2012.

${ }^{16}$ Schütte, A., Hummel, D., and Hitzel, S.M., "Flow Physics Analyses of a Generic Unmanned Combat Aerial Vehicle Configuration,” Journal of Aircraft, Vol. 49, No. 6 (2012), pp. 1638-1651. doi: 10.2514/1.C031386.

${ }^{17}$ Frink, N.T., Tormalm, M., and Schmidt, S., "Three Unstructured Computational Fluid Dynamics Studies on Generic Unmanned Combat Aerial Vehicle,“ Journal of Aircraft, 2012, Vol.49: 1619-1637, 10.2514/1.C031383

${ }^{18}$ Cummings, R.M., Schuette, A., and Huebner, A.-R., "Overview of Stability and Control Estimation Methods from NATO STO Task Group AVT-201,” AIAA-Paper 2013-968, 51st AIAA Aerospace Sciences Meeting including the New Horizons Forum and Aerospace Exposition, 2013, 10.2514/6.

${ }^{19}$ Cummings, R.M., and Schuette, A., "The NATO STO AVT-201 Task Group on Extended assessment of Stability an Control Prediction Methods for NATO Air Vehicles," AIAA-Paper 2014-2000, 32nd AIAA Applied Aerodynamics Conference, Atlanta, GA, 16-20 June, 2014.

${ }^{20}$ Huber, K., Vicroy, D.D., Schütte, A., and Hübner, A.-R., "UCAV model design investigations and static low speed wind tunnel experiments to estimate control device effectiveness and S\&C capabilities," AIAA-Paper 20142002, 32nd AIAA Applied Aerodynamics Conference, Atlanta, GA, 16-20 June, 2014.

${ }^{21}$ Vicroy, D.D., Huber, and K., Loeser, T., "Dynamic low speed wind tunnel experiments and S\&C analyses of a generic high swept UCAV configurations," AIAA-Paper 2014-2003, 32nd AIAA Applied Aerodynamics Conference, Atlanta, GA, 16-20 June, 2014.

${ }^{22}$ Rein, M., Irving, J., Rigby, G., and Birch, T., "High speed static experimental investigations on a generic UCAV to estimate control device effectiveness and S\&C capabilities," AIAA-Paper 2014-2004, 32nd AIAA Applied Aerodynamics Conference, Atlanta, GA, 16-20 June, 2014.

${ }^{23}$ Liersch, C., and Huber, K., "Conceptual design and aerodynamic analyses of a generic UCAV Configuration," AIAA-Paper 2014-2001, 32nd AIAA Applied Aerodynamics Conference, Atlanta, GA, 16-20 June, 2014.

${ }^{24}$ Bergmann, A., Huebner, A.-R., and Loeser, T., "Experimental and numerical research on the aerodynamics of unsteady moving aircraft, “ Progress in Aerospace Sciences, Vol. 44, Issue 2, pp. 121-137, Febr. 2008.

${ }^{25}$ Galle, M., Gerhold, T., and Evans, J., "Technical Documentation of the DLR TAU-Code," DLR-IB 23397/A43, 1997.

${ }^{26}$ Gerhold, T., Galle, M., Friedrich, O., and Evans, J., "Calculation of Complex Three-Dimensional Configurations employing the DLR TAU-Code,” AIAA-Paper 97-0167, Jan. 1997.

${ }^{27}$ Gerhold, T, "Overview of the Hybrid RANS Code TAU,” In N. Kroll, J. Fassbender (Eds.) MEGAFLOW Numerical Flow Simulations for Aircraft, NNFM, Vol. 89, Berlin, 2005, pp. 81-92. 
${ }^{28}$ Schwamborn, D., Gerhold, T., and Heinrich, R., "The DLR TAU-Code: Recent Applications in Research and Industry," In proceedings of "European Conference on Computational Fluid Dynamics" ECCOMAS CDF 2006, Delft The Netherland, 2006.

${ }^{29}$ Spalart, P. R., and Allmaras, S. R., “A One-Equation Turbulence Model for Aerodynamic Flows, " Recherche Aerospatiale, No. 1, 1994, pp. 5-21.

${ }^{30}$ Allmaras,S.R., Johnson, F.T, and Spalart, P.R., "Modications and Clarications for the Implementation of the Spalart-Allmaras Turbulence Model," Seventh International Conference on Computational Fluid Dynamics (ICCFD7), Big Island, Hawaii, 9-13 July 2012.

${ }^{31}$ Eisfeld, B., and Brodersen, O., "Advanced Turbulence Modelling and Stress Analysis for the DLR-F6 Configuration,“ AIAA Paper 2005-4727, 23rd AIAA Applied Aerodynamics Conference, Toronto (CAN), 06.09.06.2005.

${ }^{32}$ Cecora, R.-D., Eisfeld, B., Probst, A., Crippa, S., and Radespiel, R., "Differential Reynolds Stress Modeling for Aeronautics,“ AIAA Paper 2012-0465, 50th AIAA Aerospace Sciences Meeting including the New Horizons Forum and Aerospace Exposition, 09. - 12. Jan. 2012, Nashville, Tennesee, USA.

${ }^{33}$ Kalitzin, G., "Validation and development of two-equation turbulence models," In Validation of CFD codes and assessment of turbulence models. (W. Haase et al., eds.). Notes on Numerical Fluid Mechanics Series Vol. 58, Vieweg, 1997, pp. 319-326.

${ }^{34}$ Kalitzin, G., and Iaccarino, G., "Turbulence modeling in an immersed-boundary RANS method," Stanford University, Center for Turbulence Research, Annual Research Briefs 2002, CA, USA, pp. 415-426.

${ }^{35}$ Boerstoel, J.W., Kassies, A., Kok, J.C., and Spekreijse. S.P., "ENFLOW, a Full-Functionality System of CFD Codes for Industrial Euler/Navier-Stokes Flow Computations," NLR TP 96286U, NLR, Amsterdam, 1996.

${ }^{36}$ Kok, J.C., "Resolving the dependence on free-stream values for the k- $\omega$ turbulence model", NLR-TP-99295, NLR, Amsterdam, 1999.

${ }^{37}$ Brandsma, F.J., Kok, J.C, Dol, H.S. and Elsenaar, A., "Leading edge vortex flow computations and comparison with DNW-HST wind tunnel data," NLR-TP-2001-238, NLR, Amsterdam, 2001.

${ }^{38}$ Dol, H.S., Kok, J.C. and Oskam, B., "Turbulence modeling for leading-edge vortex flows," AIAA-2002-0843, 2002.

${ }^{39}$ Kok, J.C., Dol, H.S., Oskam, B., and van der Ven, H., "Exra-large eddy simulation of massively separated flows," NLR-TP-2003-200, 2003.

${ }^{40}$ Kok, J. C., Soemarwoto, B. I., and Ven, H. van der, "X-LES simulations using a high-order finite-volume scheme," In S. H. Peng and W. Haase, editors, Advances in Hybrid RANS-LES Modelling. Notes on Numerical Fluid Mechanics and Multidisciplinary Design, Vol. 97, pp. 87-96. Springer (2008).

${ }^{41}$ Centaur Soft, "http://www.Centaursoft.com"

${ }^{42}$ Boelens, O. J., "CFD Analysis of the Flow Around the X-31 Aircraft at High Angle of Attack," AIAA-Paper 2009-3628, 2009.

${ }^{43}$ Boelens, O.J., Badcock, K.J., Görtz, S., Morton, S., Fritz, W., Karman Jr., S.L., Michal, T. and J.E. Lamar, "Description of the F-16XL geometry and computational grids used in CAWAPI," Journal of Aircraft, Vol. 46, No.2, 2009, pp.355-368. doi: 10.2514/34957. 